\title{
Flexural Modelling and Finite Element Analysis of FRC Beams Reinforced with PVA and Basalt Fibres and Their Validation
}

\author{
Tehmina Ayub $\mathbb{D}^{1},{ }^{1}$ Sadaqat Ullah Khan $\mathbb{D}^{2},{ }^{2}$ and Nasir Shafiq ${ }^{3}$ \\ ${ }^{1}$ Department of Civil Engineering, NED University of Engineering and Technology, Karachi 75270, Pakistan \\ ${ }^{2}$ Department of Urban and Infrastructure Engineering, NED University of Engineering and Technology, Karachi 75270, Pakistan \\ ${ }^{3}$ Civil and Environmental Engineering Department, Universiti Teknologi Petronas, 31750 Seri Iskandar, Malaysia
}

Correspondence should be addressed to Tehmina Ayub; tehminaa@hotmail.com

Received 3 August 2017; Revised 9 October 2017; Accepted 31 October 2017; Published 6 March 2018

Academic Editor: Arnaud Perrot

Copyright ( $) 2018$ Tehmina Ayub et al. This is an open access article distributed under the Creative Commons Attribution License, which permits unrestricted use, distribution, and reproduction in any medium, provided the original work is properly cited.

\begin{abstract}
A flexural capacity model for fibre-reinforced concrete (FRC) beams reinforced with PVA and basalt fibres is suggested for the rectangular beam sections. The proposed models are based on the concept of equivalent stress block parameters for both compressive and tensile stresses, similar to Eurocode and ACI code. The parameters are defined by allowing the conversion of the stress-strain models into equivalent rectangular stress blocks, similar to Eurocode 2. The flexural model is suggested to determine the loading capacity of 21 FRC beams containing up to 3\% volume fraction of PVA and basalt fibres without reinforcing bars. In order to investigate the accuracy of the proposed flexure models, finite element analysis (FEA) of the same beams was carried out using the compressive and tensile stress-strain curves. Furthermore, 21 FRC beams subjected to three-point bending were tested. The results of the flexural models showed good agreement with the load-carrying capacity of the tested FRC beams, and the results of FEA of all beams showed a good correlation with the experimental results in terms of the maximum load, load versus midspan deflection patterns, and the maximum tensile strains.
\end{abstract}

\section{Introduction}

Fibre-reinforced concrete (FRC) is concrete containing fibres. FRC is a well-established material, which is commonly used in several civil engineering-related structures. Steel fibre is the most commonly studied, but due to some drawbacks of steel fibres such as cost [1] and durability [2,3], other fibres are also considered. During the last decade, PVA and basalt fibres are studied and found to be advantageous in terms of improving structural behaviour [3-9]. The compressive and tensile stress-strain models for PVA and basalt fibre-reinforced concrete have already been explored by the authors [10, 11]; however, the application of these models for the prediction of flexure behaviour is missing in the literature.

The modelling of the compressive stress-strain behaviour of FRC containing PVA and basalt fibres is reported in [10], which revealed that the addition of both fibre types increased the compressive strength and corresponding strain and stiffness, and there is a substantial increase in the post-peak energy absorption capacity (also called "Toughness"). The tensile stress-strain behaviour of FRC reinforced with PVA and basalt fibres is also different from steel fibres [11]. Therefore, the response of PVA and basalt fibres in concrete is different and cannot be predicted through the available model of steel fibre-reinforced concrete (SFRC) [12]. The reason of unsuitability of available models is that the post-peak stress-strain response of FRC solely depends on the fibre properties including fibre modulus of elasticity, elongation, and bond characteristics [11]. Hence, there is a need to develop the flexural model for both PVA and basalt fibre-reinforced concretes.

In this paper, the analytical flexural models are proposed which are based on the compressive and tensile stress-strain laws derived from experimental results, similar to the methodology followed by Barros and Figueiras [13]. The proposed flexural model is based on the traditional equivalent rectangular stress block concept for both compressive 
TABle 1: Material and mixture composition used in the experimental program.

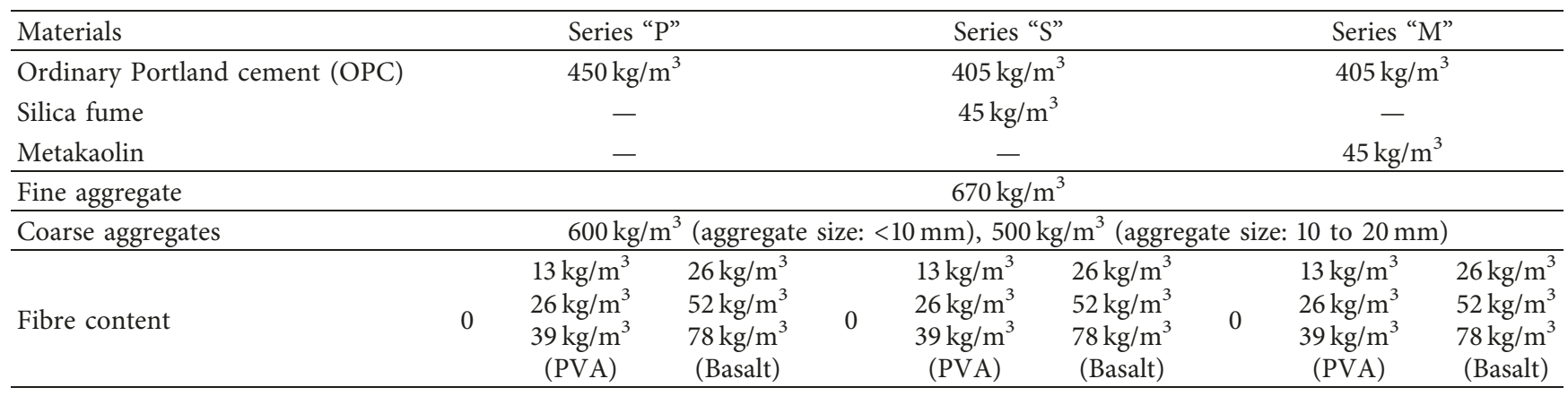

Note. In series, "P" represents plain concrete (without silica fume or metakaolin), "S" represents silica fume concrete, and "M" represents metakaolin concrete.

and tensile stress distributions across the beam cross section by converting the predicted stress-strain distributions to equivalent stress block by employing conversion parameters for the flexural models. The modelling procedure described in this paper is applicable to FRC structural elements subjected to flexural loading. It is to be noted that this paper is an allied of the previous work published [14] in which flexural test results of 21 FRC beams containing PVA and basalt fibres ( $1-3 \%$ by volume) were presented. This paper specifically focuses on the flexural modelling of the similar beams based on the suggested compressive [10] and tensile [11] stress-strain behaviours and their validation through experimental and finite element analysis approach. The endeavour is to verify the results obtained from the analytical flexural model with the results obtained from $3 \mathrm{D}$ nonlinear finite element program “ATENA 3D" and with the published experimental data by the authors [14].

\section{Behaviour and Modelling of FRC Material Properties}

It was earlier stated that the proposed analytical flexural model is based on the compressive and tensile stress-strain laws derived from experimental results, similar to the methodology followed by Barros and Figueiras [13]. The compressive stress-strain behaviour of FRC containing PVA and basalt fibres is reported in [10], and the tensile stressstrain behaviour of FRC containing PVA and basalt fibres is reported in [11]. Based on the compressive and fracture responses, the analytical expressions for predicting the compressive and tensile stress-strain were proposed and used in this paper for the development of flexural modelling. For the experimental validation of the flexural model, it is mentioned in the earlier part that the experimental work and results used in this paper have already been published in [14]. However, for the reader's interest, the summary of the flexural test performed on 21 FRC beams containing PVA and basalt fibres (1-3\% by volume) is given first.

\section{Concrete Material and Mix Details}

FRC mixes were made up of three different mix binders. The first mix binder type was made by utilising $100 \%$ cement volume. The remaining two types were blended cement system containing $10 \%$ volume of silica fume or metakaolin with $90 \%$ cement volume. For each of three binder mixes, 7 beams of the size $100 \times 200 \times 1500 \mathrm{~mm}$ were cast. The first beam (labelled as control beam) contained no fibres, while the remaining 6 beams were cast using FRC containing a volume fraction of $1 \%, 2 \%$, and 3\% PVA and basalt fibres. All 21 beams were tested to failure under three-point flexural loading. A complete detail of the mix design, investigation of the flexure test results of the beams, has been investigated by the authors and can be found in [14].

Table 1 presents the mix composition used in the experimental program. A total of three series were prepared. The average unit weight of the concrete mixes was about $2450 \mathrm{~kg} / \mathrm{m}^{3}$. The fibre volume percentages, fibre type, and binder type were the main variables that were varied to evaluate their influence on the behaviour of the FRC composites. Binder content and water-to-binder (w/b) ratio were fixed as $450 \mathrm{~kg} / \mathrm{m}^{3}$ and 0.4 . The fracture energy and the postcracking behaviour were evaluated from the flexure tests performed on 21 beam specimens of these three series. The detail of the flexure test can be found in [14]. The compression and tension behaviours were determined using specimens of all three series. For compressive behaviour, three cylinders of size $100 \times 200 \mathrm{~mm}$ from each 21 mixes were cast as per ASTM C 192/C 192 M standard [15]. For tension test, notched specimens of the size $100 \times 70 \times 600 \mathrm{~mm}$ were cast [11]. The detail is given in the forthcoming section.

Ordinary Portland cement (OPC) was used in all mixes. Kuraray RF 4000 polyvinyl alcohol (PVA) fibres and chopped basalt fibres were used as micro reinforcements for the concrete. The physical properties of both fibres are given in [14], whereas chemical composition of chopped basalt fibres is given in [10]. Fibres were added as 1,2, and $3 \%$ by the volume of concrete mix.

\section{Compressive Behaviour}

The aim of uniaxial compression testing of FRC cylindrical specimens was to define a stress-strain law to simulate the complete compression behaviour of the FRC analysed. Therefore, $100 \times 200 \mathrm{~mm}$ size cylindrical specimens were tested under deformation control condition. Testing detail and complete procedure of the compressive stress-strain modelling are given in [10]. The compression tests results of the FRC are given in Table 2, while the description of the suggested expressions is given in the subsequent section. 


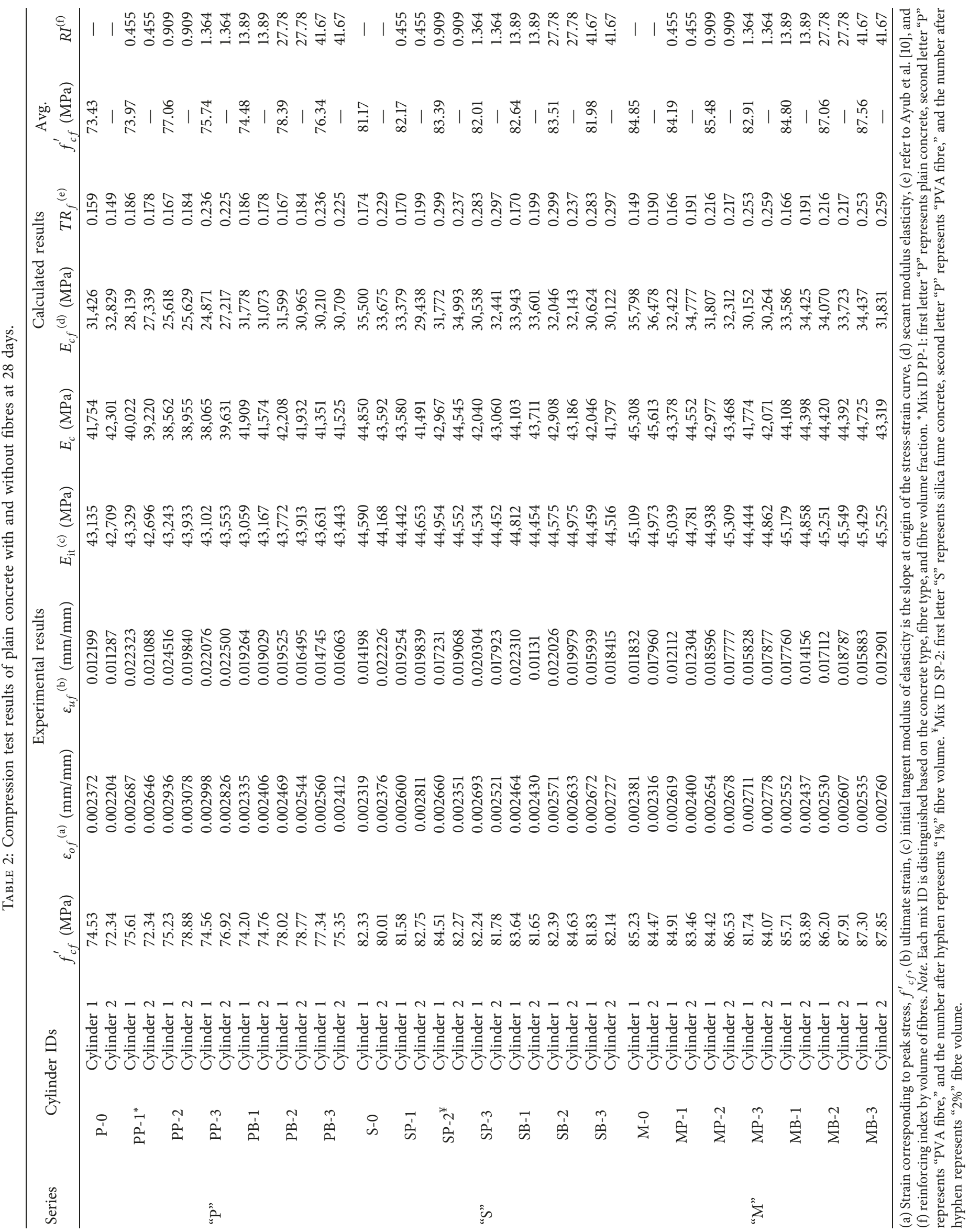


4.1. Compressive Stress-Strain Model. For plain concrete labelled as "control" and FRC, two equations are proposed for the current experimental results of the control [16] and FRC [10] cylindrical specimens. The first equation was proposed for $0<\varepsilon \leq \varepsilon_{c \text {,lim }}$, where $\varepsilon_{c \text {,lim }}$ is the strain corresponding to limiting the stress $\left(f_{c \text {,lim }}\right)$ level of $0.96 f_{c}^{\prime}$ in the falling branch. The second equation was proposed for $f_{c}>f_{c \text {,lim }}$ or $f_{c}>0.96 f_{c}^{\prime}$. A general description of the proposed model is given in Figure 1.

As there is no significant influence of fibre addition on the ascending branch of the compressive stress-strain curve, therefore, the following expression was found suitable for the current experimental data presented in Table 2 (with and without fibres).

$$
\begin{aligned}
& \text { For } 0<\varepsilon_{c} \leq \varepsilon_{c, \mathrm{lim}}, \\
& f_{c f}=\frac{n \beta f_{c f}^{\prime}\left(\varepsilon_{c f} / \varepsilon_{o f}\right)}{n \beta-1+\left(\varepsilon_{c f} / \varepsilon_{o f}\right)^{n \beta}} \quad \text { for } 0 \leq \varepsilon_{c f}<\varepsilon_{c f, \mathrm{lim}} .
\end{aligned}
$$

In (1), " $f_{c f}^{\prime}$ " and " $\varepsilon_{o f}$ " are the maximum compressive strengths of the FRC and its corresponding strain. " $n$ " and " $\beta$ " are the material parameters, where " $n$ " contributes to the toughness of the stress-strain curve, and " $\beta$ " depends on the shape of the experimental stress-strain curve. The value of " $n$ " used in the current investigation is 3 , and the expression of " $\beta$ " was same as recommended by Hsu and Hsu [17] and is given as follows:

$$
\begin{aligned}
& \beta=\left(\frac{f_{c}^{\prime}}{65.23}\right)^{3}+2.59 \text { (for control specimens), } \\
& \beta=\frac{1}{1-\left(E_{c f} / E_{\mathrm{it}}\right)}(\text { for FRC specimens), }
\end{aligned}
$$

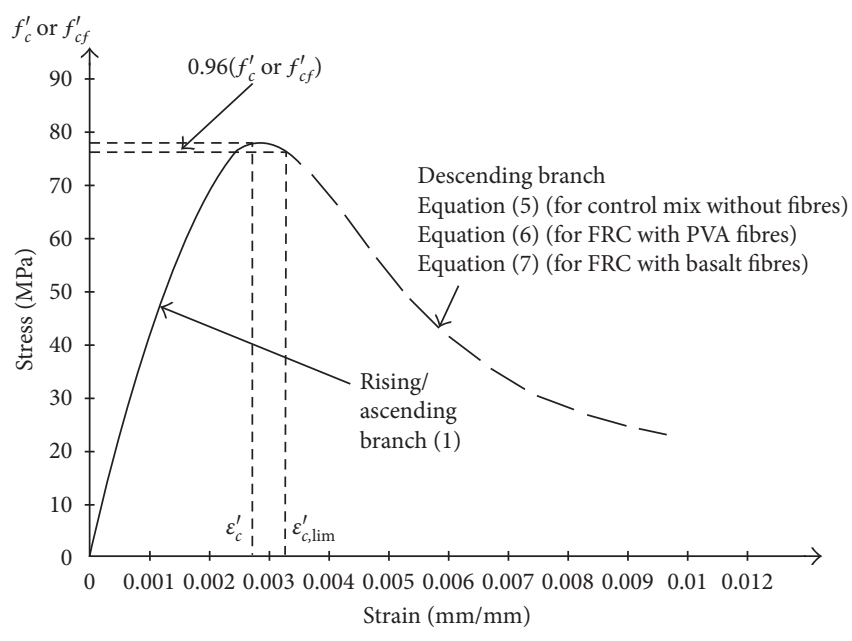

Figure 1: Description of the proposed compressive stress-strain model.

where $f_{c}^{\prime}$ is the compressive strength of the control specimens (without fibres) in (2). In (3), " $E_{c f}$ " is the secant modulus of elasticity $f_{c f}^{\prime} / \varepsilon_{o f}$. " $E_{\text {it }}$ " is the initial tangent modulus, which slightly decreased by the addition of fibres. The analysis of the results of " $E_{\mathrm{it}}$ " shows that the expression suggested by Mansur et al. [18] suits well for the current data of FRC. The expression suggested by Mansur et al. [18] for the cylinder size of $100 \times 200 \mathrm{~mm}$ is as follows:

$$
E_{\mathrm{it}}=\left(10,300-400 V_{f}\right) \sqrt[3]{f_{c f}^{\prime}}(\text { in } \mathrm{MPa}) .
$$

For $\varepsilon_{c}>\varepsilon_{c \text {,lim }}$, the following expressions are suggested for the control specimens (without fibres):

$$
f_{c}=\frac{f_{c, \lim }}{1+0.1(n-1)\left[\left\{\left(\varepsilon_{c} / \varepsilon^{\prime}{ }_{c}\right)-1\right\} /\left\{\left(\varepsilon_{c, \mathrm{lim}} / \varepsilon^{\prime}{ }_{c}\right)-1\right\}\right]^{\{1+0.1(n-1)\}}} \text { (no fibre specimen). }
$$

For FRC containing PVA fibres, the suggested expression for descending branch $\left(\varepsilon_{c f}>\varepsilon_{c f, \text { lim }}\right)$ is as follows:

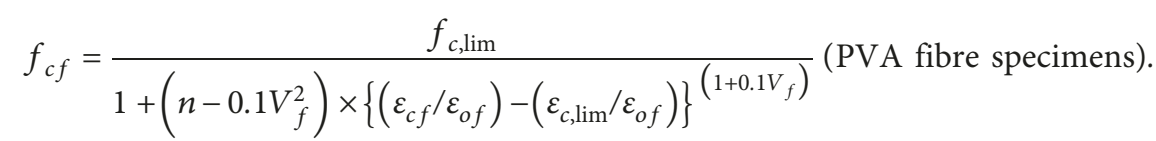

For FRC containing basalt fibres, the expression for descending branch $\left(\varepsilon_{c f}>\varepsilon_{c f, \text { lim }}\right)$ is as follows:

$$
f_{c f}=f_{c, \lim } \times \exp \left[\left(n-1-0.1 V_{f}^{2}\right) \times\left\{\frac{\varepsilon_{c f}}{\varepsilon_{o f}}-\frac{\varepsilon_{c, \lim }}{\varepsilon_{o f}}\right\}^{\left(1-0.1 V_{f}\right)}\right] \text { (basalt fibre specimens) }
$$




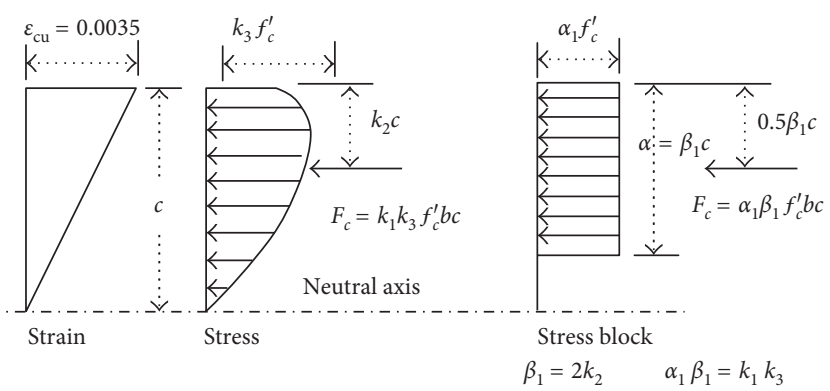

FIGURE 2: Equivalent rectangular compressive stress block (adopted from ACI 363R-92 [19] and ACI 318-08 [20]).

TABLE 3: Estimated coefficients $k_{2}, k_{1}, \alpha_{1}$, and $\beta_{1}$.

\begin{tabular}{|c|c|c|c|c|c|c|c|c|c|c|c|c|c|c|c|c|c|}
\hline \multirow{3}{*}{ Series } & \multirow{3}{*}{ Cylinder IDs } & \multicolumn{8}{|c|}{$\begin{array}{c}\text { Coefficients } k_{2}, k_{1}, \alpha_{1} \text {, and } \beta_{1} \text { using compressive } \\
\text { stress-strain relationship }\end{array}$} & \multicolumn{8}{|c|}{$\begin{array}{c}\text { Coefficients } k_{2}, k_{1}, \alpha_{1} \text {, and } \beta_{1} \text { using } \\
\text { experimental results }\end{array}$} \\
\hline & & \multicolumn{4}{|c|}{ Cylinder 1} & \multicolumn{4}{|c|}{ Cylinder 2} & \multicolumn{4}{|c|}{ Cylinder 1} & \multicolumn{4}{|c|}{ Cylinder 2} \\
\hline & & $k_{2}$ & $k_{1}$ & $\alpha_{1}$ & $\beta_{1}$ & $k_{2}$ & $k_{1}$ & $\alpha_{1}$ & $\beta_{1}$ & $k_{2}$ & $k_{1}$ & $\alpha_{1}$ & $\beta_{1}$ & $k_{2}$ & $k_{1}$ & $\alpha_{1}$ & $\beta_{1}$ \\
\hline \multirow{7}{*}{ "P" } & P-0 & 0.424 & 0.640 & 0.68 & 0.85 & 0.469 & 0.559 & & & 0.491 & 0.597 & & 0.98 & 0.504 & 0.551 & 0.59 & 0.84 \\
\hline & PP-1 & 0.373 & 0.699 & 0.84 & 0.75 & 0.377 & .671 & & & 436 & 646 & & 0.87 & .440 & & 0.65 & 0.88 \\
\hline & PP-2 & 0.359 & 0.713 & 0.89 & 0.72 & 0.348 & 0.698 & 0.90 & 0.70 & 0.399 & 0.718 & 0.81 & 0.80 & 0.393 & 0.696 & 0.80 & 0.79 \\
\hline & PP-3 & 0.348 & 0.668 & 0.86 & 0.70 & 0.368 & 0.689 & 0.84 & 0.74 & 0.427 & 0.627 & 0.66 & 0.85 & 0.400 & 0.716 & 0.81 & 0.80 \\
\hline & & 0.433 & & 0.65 & 0.87 & 0.416 & 0.656 & & & & & & 0.89 & 0.470 & & & 0.94 \\
\hline & PB & 0.391 & .72 & 0.83 & 0.78 & 0.392 & 0.7 & 0.76 & 0.7 & 0 & & & 0.94 & 40 & & 0.66 & 0.88 \\
\hline & & 0.390 & 0.68 & 0.78 & 0.78 & 0.417 & 0.6 & 0.64 & & 0.4 & & & 0.85 & & & & 1.30 \\
\hline \multirow{7}{*}{ "S" } & & 454 & 0.580 & 0.57 & 0. & 0.431 & 0.6 & 0.6 & 0. & 0.4 & & 0. & 0.86 & 10 & & 0 . & 0.82 \\
\hline & & 385 & 0.67 & 0.7 & 0. & 0.3 & & & & & & & 0.84 & 0.4 & & 66 & 0.89 \\
\hline & & 0.374 & 0.719 & 0.86 & 0.75 & 0.382 & 0.6 & 0.82 & 0.76 & 0.369 & 0.7 & 0.93 & 0.74 & 0.4 & & 0.76 & 0.81 \\
\hline & & 0.375 & 0.683 & 0.82 & 0.75 & 0.388 & 0.690 & 0.80 & 0.7 & 0.449 & 0.703 & 0.70 & 0.90 & 0.410 & & 0.77 & 0.82 \\
\hline & & 0.412 & & 0.70 & 0.82 & 0.435 & 0.575 & 0.56 & 0.8 & & 0.679 & 0.68 & 0.80 & 0.398 & 0.6 & 0.70 & 0.80 \\
\hline & & 0.382 & & 0.84 & 0. & 0.390 & 0.653 & 0.7 & 0 . & & & & 0.66 & 0.350 & & 0.72 & 0.70 \\
\hline & SB-3 & 0.376 & & 0.82 & 0.75 & 0.370 & 0.727 & 0.83 & 0.74 & 0.367 & 0.774 & 0.77 & 0.73 & 0.375 & 0.669 & 0.76 & 0.75 \\
\hline \multirow{7}{*}{ "M" } & M-0 & 0.399 & 0.805 & 0.91 & 0.80 & 0.403 & 0.801 & 0.89 & 0.8 & 0.472 & 0.767 & 0.73 & 0.94 & 0.454 & 0.664 & 0.66 & 0.91 \\
\hline & MP-1 & 0.378 & & 0.85 & 0.76 & 0.404 & & 0.72 & & & & 0.67 & 1.04 & 0.439 & 0.691 & 0.71 & 0.88 \\
\hline & MP-2 & 0.373 & 0.690 & 0.83 & 0.75 & 0.373 & 0.705 & 0.85 & 0.75 & 0.373 & 0.729 & 0.88 & 0.75 & 0.412 & 0.729 & 0.80 & 0.82 \\
\hline & MP-3 & 0.371 & 0.718 & 0.87 & 0.74 & 0.363 & 0.712 & 0.88 & 0.73 & 0.386 & 0.746 & 0.87 & 0.77 & 0.409 & 0.717 & 0.79 & 0.82 \\
\hline & MB-1 & 0.384 & 0.72 & 0.84 & 0.77 & 0.417 & 0.635 & 0.65 & 0.83 & 0.323 & 0.704 & 0.70 & 0.65 & 0.372 & 0.558 & 0.64 & 0.74 \\
\hline & MB-2 & 0.402 & 0.65 & 0.73 & 0.80 & 0.385 & 0.656 & 0.72 & 0.77 & 0.448 & 0.678 & 0.68 & 0.90 & 0.330 & 0.558 & 0.72 & 0.66 \\
\hline & MB-3 & 0.387 & 0.71 & 0.82 & 0.77 & 0.37 & 0.693 & 0.80 & 0.74 & 0.410 & 0.712 & 0.71 & 0.82 & 0.335 & 0.641 & 0.81 & 0.67 \\
\hline
\end{tabular}

$k_{1}$ is the ratio of average to maximum compressive stress in beam $=$ area under the curve $\times \varepsilon_{\mathrm{cu}} /\left(k_{3} f_{c}^{\prime}\right), k_{2}$ is the ratio of depth to compressive resultant to neutral axis depth, and $k_{3}$ is the ratio of maximum stress in beam to maximum stress in corresponding axially loaded cylinder $=0.85$ [19].

Note that in (5), the term " $f_{c}$ " represents the compressive strength of plain concrete, whereas the term " $f_{c f}$ " in (6) and (7) represents the compressive strength of FRC. Using the experimental results given in Table 2 and (1)-(7), the complete investigation can be found in $[10,16]$.

4.2. Compressive Stress Block. For FRC, the designed compression stress distribution is simplified using conversion factors " $\alpha_{1}$ " and " $\beta_{1}$ " applied to the design compressive strength and its corresponding depth within the beam so that a rectangular stress block is generated from a parabolic stress distribution to a rectangular stress distribution, as recommended in ACI 363R-92 [19]. A typical equivalent rectangular block, adopted from [19], is shown in Figure 2. In the following figure, the value of ultimate strain is taken as
0.0035, instead of 0.003 recommended in ACI 363R-92 [19] and ACI 318-08 [20]. The reason for selecting the value of 0.0035 is based on the results of the compressive strain corresponding to the maximum compressive strength. Canadian standard CSA [21] and European standard Eurocode 2 [22] also suggest the value of ultimate strain as 0.0035 . Since the compressive behaviour of FRC will not vary significantly from that of normal concrete or concrete without fibres, the same concept can be used for FRC in compression. The notations used in this research for the equivalent rectangular stress block parameters at any stress state are shown in Figure 2.

The coefficient $k_{3}$ which had been developed already in ACI 363R-92 [19] is equal to 0.85. This coefficient helps in defining the peak stress of in-place stress-strain relationship of concrete, as defined in the preceding section. The proposed 
TABle 4: Tension test results at 28 days.

\begin{tabular}{|c|c|c|c|c|c|c|c|c|c|}
\hline \multirow{3}{*}{ Series } & \multirow{3}{*}{$\begin{array}{l}\text { Specimen } \\
\text { ID }\end{array}$} & \multicolumn{8}{|c|}{ Direct tension test result } \\
\hline & & \multicolumn{2}{|c|}{ At cracking } & \multicolumn{2}{|c|}{ Postcracking } & \multicolumn{2}{|c|}{ At cracking } & \multicolumn{2}{|c|}{ Postcracking } \\
\hline & & $\begin{array}{l}\text { Load }\left(P_{\mathrm{cr}}\right) \\
(\mathrm{kN})\end{array}$ & $\begin{array}{c}\text { Elongation } \\
(\mathrm{mm})\end{array}$ & $\begin{array}{l}\text { Load }\left(P_{\mathrm{pc}}\right) \\
(\mathrm{kN})\end{array}$ & $\begin{array}{c}\text { Elongation } \\
(\mathrm{mm})\end{array}$ & $\begin{array}{c}\text { Stress }\left(f_{c}^{\prime}\right) \\
(\mathrm{MPa})\end{array}$ & $\begin{array}{l}\text { Strain }\left(\varepsilon_{\mathrm{cr}}\right) \\
(\mathrm{mm} / \mathrm{mm})\end{array}$ & $\begin{array}{c}\text { Stress }\left(f_{\mathrm{pc}}\right) \\
(\mathrm{MPa})\end{array}$ & $\begin{array}{c}\text { Strain }\left(\varepsilon_{\mathrm{pc}}\right) \\
(\mathrm{mm} / \mathrm{mm})\end{array}$ \\
\hline \multirow{7}{*}{ "P" } & $\mathrm{P}-0$ & 26.30 & 0.02428 & - & - & 5.367 & 0.0001214 & - & - \\
\hline & PP-1 & 26.44 & 0.02321 & 10.617 & 0.0363 & 5.396 & 0.0001160 & 2.167 & 0.0001817 \\
\hline & PP-2 & 30.91 & 0.02483 & 17.442 & 0.1015 & 6.308 & 0.0001242 & 3.559 & 0.0005077 \\
\hline & PP-3 & 26.63 & 0.02539 & 21.677 & 0.1009 & 5.436 & 0.001269 & 4.424 & 0.0005047 \\
\hline & PB-1 & 27.27 & 0.02428 & - & - & 5.564 & 0.0001214 & - & - \\
\hline & PB-2 & 31.23 & 0.02578 & - & - & 6.374 & 0.0001289 & - & - \\
\hline & PB-3 & 27.95 & 0.03046 & - & - & 5.703 & 0.0001523 & - & - \\
\hline \multirow{6}{*}{ "S" } & S-0 & 27.02 & 0.02482 & - & - & 5.515 & 0.0001241 & - & - \\
\hline & SP-1 & 29.15 & 0.02201 & 10.72 & 0.04157 & 5.949 & 0.0001100 & 2.188 & 0.0002078 \\
\hline & SP-2 & 30.73 & 0.03151 & 15.672 & 0.08832 & 6.271 & 0.0001576 & 3.198 & 0.0004416 \\
\hline & SP-3 & 31.24 & 0.03703 & 18.623 & 0.08505 & 6.375 & 0.0001851 & 3.801 & 0.0004253 \\
\hline & SB-1 & 29.76 & 0.030212 & - & - & 6.073 & 0.0001511 & - & - \\
\hline & SB-2 & 31.37 & 0.036938 & - & - & 6.402 & 0.0001847 & - & - \\
\hline \multirow{8}{*}{ "M" } & SB-3 & 28.80 & 0.024795 & - & - & 5.879 & 0.0001240 & - & - \\
\hline & M-0 & 30.24 & 0.02505 & - & - & 6.172 & 0.0001252 & - & - \\
\hline & MP-1 & 31.35 & 0.02745 & 11.928 & 0.04299 & 6.399 & 0.0001373 & 2.434 & 0.0002150 \\
\hline & MP-2 & 32.08 & 0.03542 & 17.861 & 0.04268 & 6.547 & 0.0001771 & 3.645 & 0.0002134 \\
\hline & MP-3 & 29.84 & 0.03377 & 19.28 & 0.06781 & 6.089 & 0.0001688 & 3.935 & 0.0003390 \\
\hline & MB-1 & 29.16 & 0.02525 & - & - & 5.952 & 0.0001262 & - & - \\
\hline & MB-2 & 33.53 & 0.03408 & - & - & 6.843 & 0.0001704 & - & - \\
\hline & MB-3 & 34.68 & 0.03097 & - & - & 7.078 & 0.0001549 & - & - \\
\hline
\end{tabular}

stress-strain relationships were selected to derive the coefficients $k_{1}$ and $k_{2}$. Since the proposed compressive stressstrain model for the ascending branch is an indefinite integral, therefore, area under the curve and the centroid of area for all types of FRC up to ultimate compressive strain $\varepsilon_{\mathrm{cu}}$ were estimated with the help of the trapezoidal rule. The centroid of the area relative to extreme fibre strain yielded the coefficient $k_{2}$. The coefficient $k_{1}$ was determined such that the area of compressive stress-strain relationship was set equal to an equivalent rectangular stress distribution over the entire compressive zone. The estimated areas under the curve and the centroid of areas for all FRC, using experimental results and proposed compressive stress-strain relationships, are presented in [23]. The values of coefficients $k_{1}$ and $k_{2}$ after following procedures are shown in Table 3. In the same table, the results of coefficients are compared with coefficients obtained from experimental compressive stress-strain curves to assess the precision of compressive stress-strain relationship. The proposed rectangular compressive stress block is defined by a width equal to $\alpha_{1} f_{c}^{\prime}$ and depth $\beta_{1} c$, as done in ACI 318-08 [20]. The proposed rectangular compressive stress block is shown in Figure 2, while the estimation of coefficients $\alpha_{1}$ and $\beta_{1}$ using coefficients $k_{3}, k_{1}$, and $k_{2}$ is as follows:

$$
\begin{aligned}
\alpha_{1} \beta_{1} & =k_{1} k_{3}, \\
\beta_{1} & =2 k_{2},
\end{aligned}
$$

where the coefficient $k_{3}$ is 0.85 . The estimated coefficients $k_{1}$ and $k_{2}$ are given in Table 3 . It is to be noted that the values of coefficient $\beta_{1}$, according to ACI 318-08 [20], should be greater than or equal to 0.65 for $f_{c}^{\prime}>28 \mathrm{MPa}$.

\section{Tensile Behaviour}

The aim of the uniaxial tension testing of the FRC specimens was to define a stress-strain law to simulate the complete tensile behaviour. Therefore, $70 \times 70 \times 600 \mathrm{~mm}$ size notched specimens were tested under deformation control condition. The testing detail and the complete procedure of the tensile stress-strain modelling are given in [11]. The tension tests results of FRC are given in Table 4, while the description of the suggested expressions is given in the subsequent section.

5.1. Tensile Stress-Strain Model. For the prediction of the tensile stress-strain $\left(f_{t}-\varepsilon_{t}\right)$ behaviour of FRC reinforced with PVA and basalt fibres, two models are proposed. The complete investigation of the proposed model can be found in [11]. For the elastic behaviour in tension, a new formulation is suggested with an assumption that when the composite specimen is stressed as shown in Figure 3, the PVA and basalt fibres will be firmly bonded with the matrix so that no slippage can occur at the fibre-matrix interface.

Considering the idealized stress-strain behaviour shown in Figure 3, the following model is suggested for the "elastic behaviour in tension," that is, the pre-peak branch of the tensile stress-strain curve:

$$
f_{t}=\frac{\omega\left(\varepsilon_{t} / \varepsilon_{\mathrm{cr}}\right) f_{c}^{\prime}}{\omega-1+\left(\varepsilon_{t} / \varepsilon_{\mathrm{cr}}\right)^{\omega}} .
$$

In (9), $f_{c}^{\prime}$ is the maximum tensile strength (at cracking), $\varepsilon_{\mathrm{cr}}$ is the cracking strain corresponding to $f_{c}^{\prime}$, and $\omega$ is the 


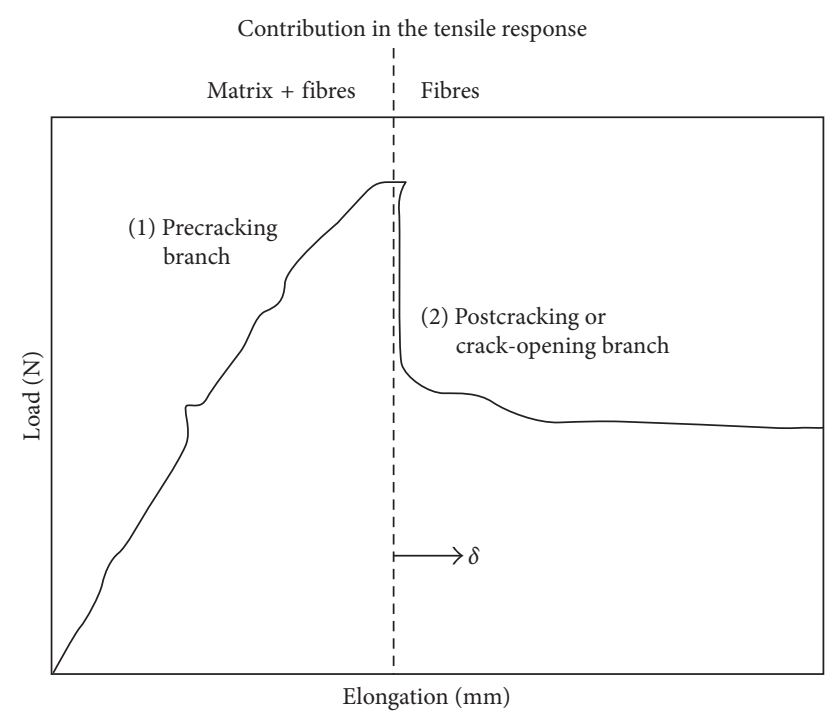

FIGURE 3: General response of concrete under direct tension [11].

material parameter. The parameter $\omega$ strongly depends on the initial modulus of elasticity $\left(E_{\mathrm{it}}\right)$, tensile strength of FRC $\left(f_{t}^{\prime}\right)$, and its corresponding cracking strain $\left(\varepsilon_{\mathrm{cr}}\right)$. The parameter $\omega$ decides the shape of the pre-peak branch of the tensile stress-strain curves. The expression for $\omega$ is expressed as

$$
\omega=c f_{t}^{\prime}\left[\frac{E_{\mathrm{it}}}{\left(f_{t}^{\prime} / \varepsilon_{\mathrm{cr}}\right)}\right] \text { or } \omega=c E_{\mathrm{it}} \varepsilon_{\mathrm{cr}} .
$$

In (10), $c$ is a coefficient that depends on the composite/matrix type. The coefficient $c$ decides the required shape of the initial branch of the tensile stress-strain curve. In this research, a suitable value of $c$ for concrete was found as 1.5 for a concrete-based composite. $E_{\text {it }}$ is the initial tangent modulus of elasticity of tensile stress-strain curves of FRC and is the same as given in Table 2 for the compressive stress-strain curves of FRC. The proposed model for the prepeak branch is unique, as no such model was proposed to capture the curvilinear shape of the curve.

For the postcracking behaviour, the mathematical model can be found in $[11,24]$.

\section{Development of the Flexural Capacity Model for the Rectangular FRC Beam Section}

In general, a beam element subjected to flexural loads may experience three basic stages of stress states, as shown in Figure 4. The stages assume that the element will reach the first cracking strain in tension before reaching the compression inelastic strain and are expressed as follows:

(1) Stage I: linear elastic stress-strain relationship in both compression and tension, that is, stress state before the material cracks in tension

(2) Stage II: linear elastic stress-strain relationship in compression while tension is in inelastic distribution, that is, the stress state after the material has reached cracking strain before compression strain (corresponding to inelastic stress) is reached

(3) Stage III: inelastic stress distribution for both compression and tension stress-strain fields, that is, the stress state after the material has cracked in tension and crushed in compression

6.1. Elastic Stage (Stage I) and Cracking Stage Models (Stage II). The elastic stage and cracking stage models are bit similar. The difference between these two stages is that concrete tensile strain $\varepsilon_{t}$ just reached the maximum and the compressive strain $\varepsilon_{c}$ was within the elastic range at this Stage I (refer to Figure 4(a)), while at the cracking stage, the concrete tensile strain $\varepsilon_{t}$ just reached to yield strain, while the compressive strain was within the elastic range (refer to Figure 4(b)).

At first, the results were estimated for the cracking stage or Stage II condition (refer to Figure 4(b)); that is, at this stage, the concrete tensile stresses will be equivalent to $f_{\mathrm{tf}}^{\prime}$. It is assumed that the postcracking stress $\sigma_{\mathrm{pc}}$ or $f_{\mathrm{pc}}$ was negligible or zero at cracking. Therefore, the flexural load at cracking, that is, $F_{t}$, was calculated using the governing stress $f_{\text {tf }}^{\prime}$ assuming that the whole cross section was effective at cracking. $F_{t}$ (refer to Figure $\left.4(\mathrm{~b})\right)$ is given as follows:

$$
\begin{gathered}
F_{t}=\frac{1}{2} f_{t}^{\prime} \text { (area of tension zone), } \\
F_{t}=\frac{1}{2} f_{t}^{\prime}\left(b \times \frac{h}{2}\right) .
\end{gathered}
$$

In (12), $b$ and $h$ are the width and height of the rectangular beam section. Flexural capacity $\left(M_{\mathrm{cr}}\right)$ of FRC using cracking stress $\sigma_{\text {cc }}$ or $f_{t}^{\prime}$ (refer to Figure $4(\mathrm{~b})$ ) is as follows:

$$
M_{\mathrm{cr}}=\frac{1}{2} f_{t}^{\prime}\left(b \times \frac{h}{2}\right) \times\left(\frac{2}{3} h\right) \text { or } F_{t} \times\left(\frac{2}{3} h\right) \text {. }
$$

Using (13), the cracking load $\left(P_{\mathrm{cr}}\right)$ for the beam subjected to single point load acting at the centre of the beam can be calculated as follows:

$$
M_{\mathrm{cr}}=P_{\mathrm{cr}} \times \frac{L}{4} .
$$

In (14), $L$ represents the beam span.

6.2. Ultimate Stage Model (Stage III). Using the approach similar to Eurocode 2 [22] and ACI 318-08 [20], an ultimate stage model for the flexural capacity of FRC beams reinforced with PVA and basalt fibres is suggested for rectangular sections using equivalent stress blocks for both tensile and compressive stresses. The parameters are defined by allowing the conversion of the stress-strain models into equivalent rectangular stress blocks, similar to Eurocode 2 [22]. For the flexural modelling of FRC, the suggested stressstrain model is presented in Figure 4(c). In order to determine the flexural capacity at ultimate, the depth of the 


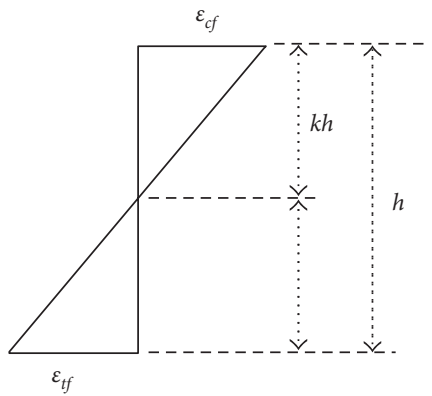

(a)
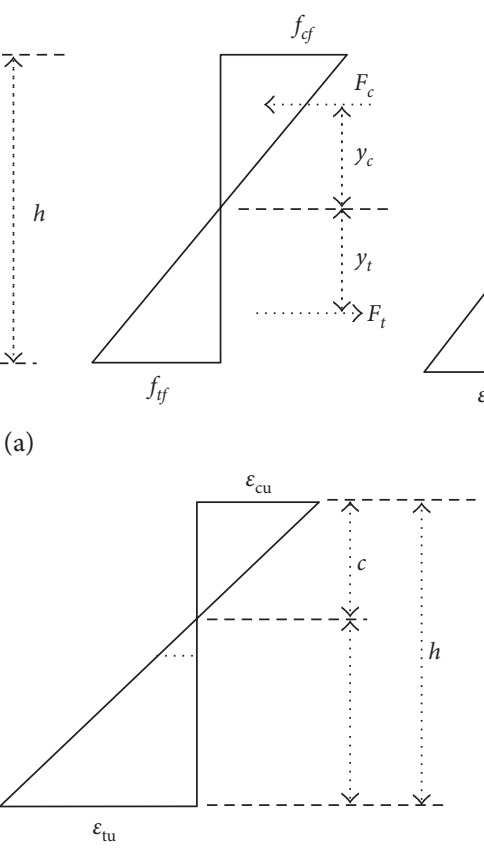

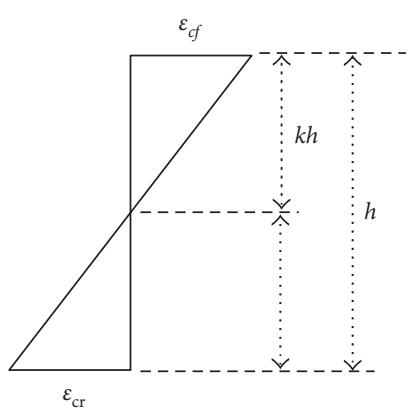

(b)

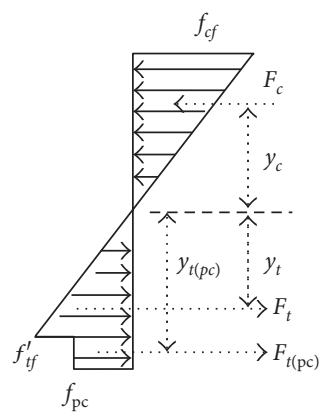

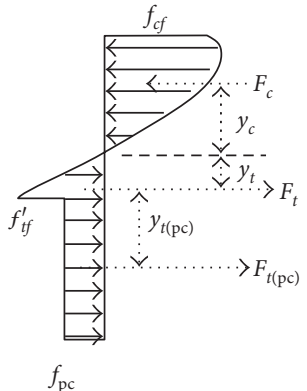

(c)

Figure 4: Three stages of stress-strain response in flexure. (a) Stage I: elastic behaviour in compression and tension. (b) Stage II: elastic behaviour in compression and plastic behaviour in tension (cracking stage). (c) Stage III: nonlinear behaviour in compression and plastic behaviour in tension (ultimate stage).

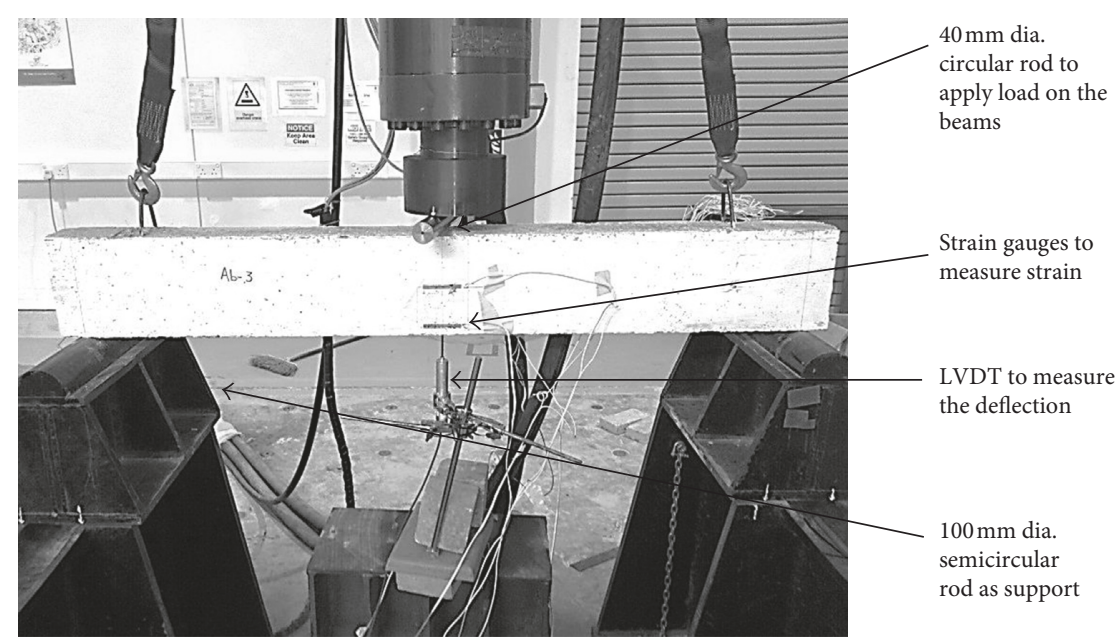

Figure 5: Typical loading arrangement of beams [14].

neutral axis " $c$ " was determined by considering the strain diagram shown in Figure 4(c) as follows:

$$
\varepsilon_{\mathrm{tu}}=\left(\frac{h-c}{c}\right) \times \varepsilon_{\mathrm{cu}} .
$$

In (15), $\varepsilon_{\mathrm{tu}}$ is the ultimate tensile strain corresponding to $\sigma_{\mathrm{pc}} \cdot \varepsilon_{\mathrm{cu}}$ is the ultimate compressive strain assumed as 0.0035 , $h$ is the depth of the rectangular beam section, and $c$ is the depth of the neutral axis from the extreme compression fibre (refer to Figure 4(c)).

After determining the neutral axis depth, the next step was to determine the tension force $F_{t(\mathrm{pc})}$. As failure of FRC beams occurred from the tension side, the dominating tension force was estimated as follows:

$$
F_{t(\mathrm{pc})}=\sigma_{\mathrm{pc}} \times b(h-c) .
$$




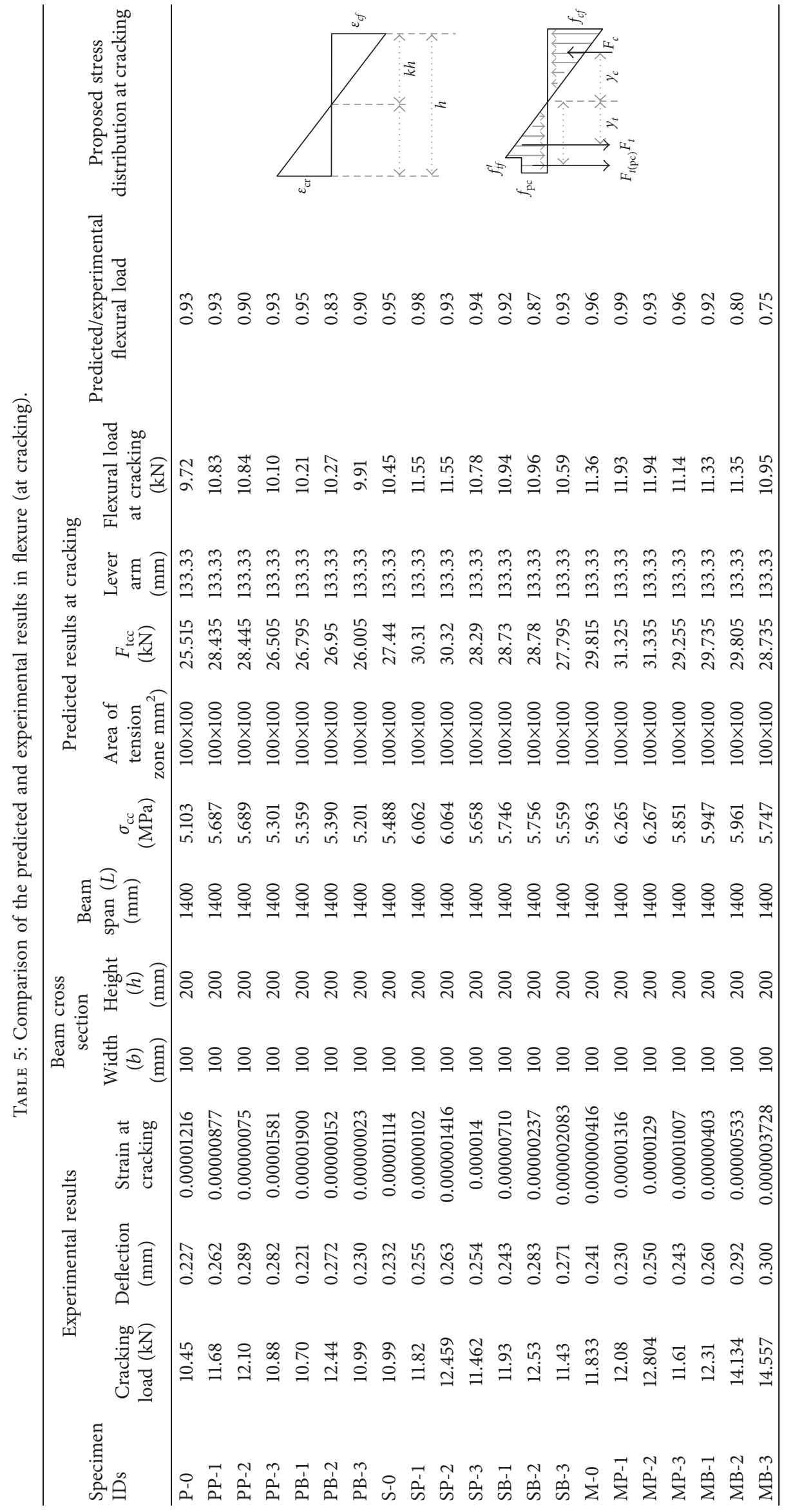


TABLE 6: Summary of the initial material input parameters, FEA parameters, and results.

\begin{tabular}{|c|c|c|c|c|c|c|c|c|c|c|}
\hline \multirow[b]{2}{*}{ Series } & \multirow[b]{2}{*}{$\begin{array}{c}\text { Beam } \\
\text { IDs }\end{array}$} & \multirow[b]{2}{*}{$\begin{array}{c}\text { Cylinder }^{(\mathrm{a})} \\
\text { compressive } \\
\text { strength }\left(f_{\mathrm{cu}}\right) \\
(\mathrm{MPa})\end{array}$} & \multicolumn{4}{|c|}{ Trial parameters } & \multicolumn{4}{|c|}{ FE results for the monitoring points } \\
\hline & & & $\begin{array}{l}\text { Elastic }^{(\mathrm{b})} \\
\text { modulus } \\
(E)(\mathrm{MPa})\end{array}$ & $\begin{array}{l}\text { Tensile }^{(\mathrm{c})} \\
\text { strength } \\
\left(\left(f_{t}\right)\right) \\
(\mathrm{MPa})\end{array}$ & $\begin{array}{c}\text { Fracture }^{(\mathrm{d})} \\
\text { energy } \\
\left(G_{f}\right) \\
(\mathrm{N} / \mathrm{mm})\end{array}$ & $\begin{array}{l}\text { Prescribed }^{(\mathrm{e})} \\
\text { displacement } \\
\quad(\mathrm{mm})\end{array}$ & $\begin{array}{l}\text { Load } \\
(\mathrm{kN})\end{array}$ & $\begin{array}{c}2 \\
\text { Deflection } \\
(\mathrm{mm})\end{array}$ & $\begin{array}{c}3 \\
\text { Maximum }^{(\mathrm{f})} \\
\text { strain at }^{\text {bottom }} \\
(\mathrm{mm} / \mathrm{mm})\end{array}$ & $\begin{array}{c}\text { Maximum } \\
\text { strain at top } \\
(\mathrm{mm} / \mathrm{mm})\end{array}$ \\
\hline \multirow{7}{*}{ "P” } & $\mathrm{P}-0$ & 73.43 & 43.00 & 3.62 & 0.11 & 0.01 & 10.416 & 0.2199 & 0.0001238 & 0.00009936 \\
\hline & PP-1 & 73.97 & 38.00 & 4.68 & 0.0068 & 0.01 & 11.968 & 0.2599 & 0.0001151 & 0.0001189 \\
\hline & PP-2 & 77.06 & 36.00 & 4.908 & 0.0163 & 0.01 & 12.048 & 0.2899 & 0.0001239 & 0.0001284 \\
\hline & PP-3 & 75.74 & 32.50 & 3.8 & 0.09 & 0.01 & 10.264 & 0.275 & 0.0001693 & 0.0001266 \\
\hline & PB-1 & 74.48 & 41.00 & 4.45 & 0.061 & 0.01 & 10.632 & 0.2199 & 0.00009742 & 0.0001001 \\
\hline & PB-2 & 78.39 & 40.00 & 4.58 & 0.125 & 0.01 & 12.352 & 0.2699 & 0.0001582 & 0.0001227 \\
\hline & PB-3 & 76.34 & 41.70 & 4.26 & 0.0853 & 0.01 & 10.982 & 0.2299 & 0.0001326 & 0.0001043 \\
\hline \multirow{6}{*}{ "S" } & S-0 & 81.17 & 42.50 & 4.80 & 0.06 & 0.01 & 11.512 & 0.2299 & 0.0001019 & 0.0001045 \\
\hline & SP-1 & 82.17 & 39.2 & 4.75 & 0.0193 & 0.01 & 11.594 & 0.2499 & 0.0001107 & 0.0001141 \\
\hline & SP-2 & 83.39 & 38.3 & 4.82 & 0.0693 & 0.01 & 11.788 & 0.2599 & 0.0001151 & 0.0001188 \\
\hline & SP-3 & 82.01 & 42.00 & 3.5 & 0.15 & 0.01 & 11.214 & 0.2499 & 0.0001119 & 0.0001666 \\
\hline & SB-1 & 82.64 & 41.00 & 4.71 & 0.009 & 0.01 & 11.85 & 0.2599 & 0.0001573 & 0.0001181 \\
\hline & SB-2 & 83.51 & 38.00 & 4.60 & 0.115 & 0.01 & 12.168 & 0.2799 & 0.0001660 & 0.0001276 \\
\hline \multirow{8}{*}{ "M" } & SB-3 & 81.98 & 37.00 & 4.55 & 0.09 & 0.01 & 11.420 & 0.2699 & 0.0001615 & 0.0001232 \\
\hline & M-0 & 84.85 & 41.80 & 4.95 & 0.04 & 0.01 & 11.820 & 0.2399 & 0.0001064 & 0.0001091 \\
\hline & MP-1 & 84.19 & 44.00 & 4.90 & 0.064 & 0.01 & 11.906 & 0.2299 & 0.0001020 & 0.0001043 \\
\hline & MP-2 & 85.48 & 43.00 & 5.25 & 0.06 & 0.01 & 12.684 & 0.2499 & 0.0001108 & 0.0001135 \\
\hline & MP-3 & 82.91 & 41.25 & 3.60 & 0.1 & 0.01 & 10.474 & 0.2399 & 0.0001352 & 0.00001032 \\
\hline & MB-1 & 84.80 & 40.00 & 5.15 & 0.04 & 0.01 & 12.268 & 0.2599 & 0.0001152 & 0.0001185 \\
\hline & MB-2 & 87.06 & 43.00 & 5.72 & 0.112 & 0.01 & 14.11 & 0.2899 & 0.0001816 & 0.0001312 \\
\hline & MB-3 & 87.56 & 40.50 & 5.98 & 0.05 & 0.01 & 14.326 & 0.2999 & 0.0001329 & 0.0001367 \\
\hline
\end{tabular}

Note. Results of average cylinder compressive strength ${ }^{(\mathrm{a})}\left(f_{c}^{\prime}\right)$ and modulus of elasticity ${ }^{(\mathrm{b})}$ were same as given in Table 2 . The results of tensile strength ${ }^{(\mathrm{c})}\left(f_{t}\right)$ are taken from Table 4 . The results of fracture energy ${ }^{(\mathrm{d})}$ were calculated using the formula given in Table 2.12 in [26]. Prescribed displacement ${ }^{(\mathrm{e})}$ is provided on trial basis. The values of maximum strain ${ }^{(\mathrm{f})}$ at the bottom and at the top were estimated by the results of the lateral displacements (in mm) by the distance between the monitoring point 3 and 4 , which was $60 \mathrm{~mm}$.

Using tension force $F_{t(\mathrm{pc})}$ (refer to Figure $4(\mathrm{c})$ ), the ultimate moment capacity was determined as follows:

$$
M_{u}=F_{t(\mathrm{pc})} \times\left(h-\frac{a}{2}\right)
$$

where depth of the proposed rectangular stress block " $a$ " was determined as follows:

$$
a=\beta_{1} c .
$$

In (18), the value of $\beta_{1}$ is estimated from the stress-strain behaviour as explained in the forthcoming section. In order to validate this model, the results of the ultimate load corresponding to the strain values of 0.0035 were compared with the numerical results, as discussed in [10].

The results of the ultimate loads were found to be close to the numerical results. Thus, proposed rectangular stress block mode concept can be used for the practical designing of the structural member made of FRC.

\section{Flexure Test Results and Analysis of FRC Beam}

The flexure testing of FRC reinforced with PVA and basalt fibres is shown in Figure 5, and the test results are presented in Table 5. All 21 beams failed in flexure exhibiting I-mode of failure. The reason for mode "I" failure is the application of single point load at the middle of the beam span, as mentioned by Sorankom and Mobasher [25]. The data required from flexural testing were failure load, failure modes, and complete load-deflection response of all the beams along with strain results, which are presented in Table 5. Further details of flexural testing and results can be found in [14].

The flexure strength of FRC beams reinforced with PVA and basalt fibres (without reinforcing bars) was estimated for cracking stage (Stage II) using flexural model shown in Figure 4. The comparison of the predicted results of the flexural strength with the experimental result (at cracking) is given in Table 5. As the beams were not containing conventional longitudinal reinforcement, it could not be possible to gather experimental data at ultimate.

\section{Load-Deflection Curves under Flexure}

The load-deflection response of all simply supported FRC beams is discussed in detailed by the authors in [14]. In this paper, those load-deflection behaviours are validated 


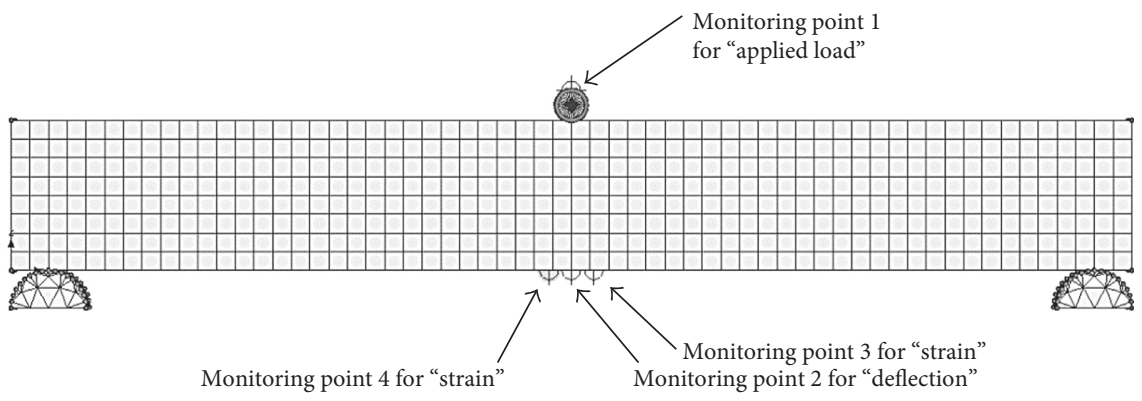

FIGURE 6: Finite element meshes and monitoring point definition.

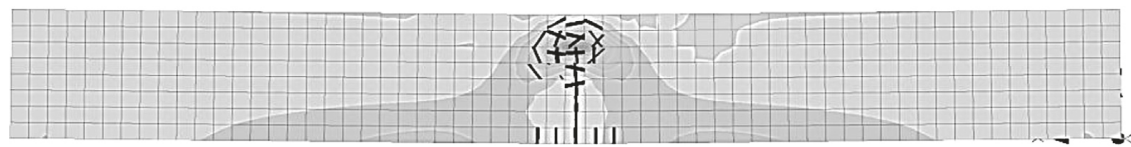

FIGURE 7: Typical crack pattern at beam failure.

TABLE 7: Comparison of finite element (FE) analysis and experimental results.

\begin{tabular}{|c|c|c|c|c|c|c|c|c|c|c|c|}
\hline \multirow[b]{2}{*}{ Series } & \multirow[b]{2}{*}{$\begin{array}{l}\text { Beam } \\
\text { IDs }\end{array}$} & \multicolumn{3}{|c|}{$\begin{array}{l}\text { Finite element analysis (FEA) } \\
\text { results }\end{array}$} & \multicolumn{3}{|c|}{ Experimental results } & \multirow{2}{*}{$\begin{array}{l}\text { Mathematical } \\
\text { model results } \\
\text { Load }(\mathrm{kN})\end{array}$} & \multicolumn{3}{|c|}{ Experimental/FEA results } \\
\hline & & $\begin{array}{l}\text { Load } \\
(\mathrm{kN})\end{array}$ & $\begin{array}{l}\text { Deflection } \\
\quad(\mathrm{mm})\end{array}$ & $\begin{array}{c}\text { Tensile } \\
\text { strain } \\
(\mathrm{mm} / \mathrm{mm})\end{array}$ & $\begin{array}{l}\text { Load } \\
(\mathrm{kN})\end{array}$ & $\begin{array}{l}\text { Deflection } \\
\quad(\mathrm{mm})\end{array}$ & $\begin{array}{c}\text { Tensile } \\
\text { strain } \\
(\mathrm{mm} / \mathrm{mm})\end{array}$ & & $\begin{array}{l}\text { Load } \\
(\mathrm{kN})\end{array}$ & $\begin{array}{l}\text { Deflection } \\
\quad(\mathrm{mm})\end{array}$ & $\begin{array}{c}\text { Tensile } \\
\text { strain } \\
(\mathrm{mm} / \mathrm{mm})\end{array}$ \\
\hline \multirow{7}{*}{ "P" } & $\mathrm{P}-0$ & 10.416 & 0.2199 & 0.0001238 & 10.45 & 0.227 & 0.0001310 & 9.72 & 0.9967 & 0.9687 & 0.9450 \\
\hline & PP-1 & 11.67 & 0.2599 & 0.0001151 & 11.68 & 0.262 & 0.0001243 & 10.83 & 0.9991 & 0.9920 & 0.9260 \\
\hline & PP-2 & 11.954 & 0.2799 & 0.0001239 & 12.10 & 0.289 & 0.0001286 & 10.84 & 0.9879 & 0.9685 & 0.9635 \\
\hline & PP-3 & 10.264 & 0.275 & 0.0001693 & 10.88 & 0.282 & 0.0001708 & 10.10 & 0.9434 & 0.9752 & 0.9912 \\
\hline & PB-1 & 10.632 & 0.2199 & 0.0000974 & 10.70 & 0.221 & 0.0001034 & 10.21 & 0.9936 & 0.9950 & 0.9422 \\
\hline & PB-2 & 12.352 & 0.2699 & 0.0001582 & 12.44 & 0.272 & 0.0001590 & 10.27 & 0.9929 & 0.9923 & 0.9950 \\
\hline & PB-3 & 10.982 & 0.2299 & 0.0001326 & 10.99 & 0.230 & 0.0001326 & 9.91 & 0.9993 & 0.9996 & 1.0000 \\
\hline \multirow{6}{*}{ "S" } & S-0 & 10.85 & 0.2299 & 0.0001019 & 10.99 & 0.232 & 0.0001020 & 10.45 & 0.9873 & 0.9909 & 0.9990 \\
\hline & SP-1 & 11.594 & 0.2499 & 0.0001107 & 11.82 & 0.255 & 0.0001297 & 11.55 & 0.9809 & 0.9800 & 0.8535 \\
\hline & SP-2 & 11.788 & 0.2599 & 0.0001151 & 12.459 & 0.263 & 0.0001468 & 11.55 & 0.9461 & 0.9882 & 0.7841 \\
\hline & SP-3 & 11.214 & 0.2499 & 0.0001119 & 11.462 & 0.254 & 0.0001736 & 10.78 & 0.9784 & 0.9839 & 0.6446 \\
\hline & SB-1 & 11.60 & 0.2399 & 0.0001063 & 11.93 & 0.243 & 0.0001610 & 10.94 & 0.9723 & 0.9872 & 0.6602 \\
\hline & SB-2 & 12.168 & 0.2799 & 0.0001660 & 12.19 & 0.283 & 0.0001699 & 10.96 & 0.9982 & 0.9890 & 0.9770 \\
\hline \multirow{8}{*}{ "M" } & SB-3 & 11.420 & 0.2699 & 0.0001615 & 11.43 & 0.271 & 0.0001666 & 10.59 & 0.9991 & 0.9959 & 0.9694 \\
\hline & M-0 & 11.820 & 0.2399 & 0.0001064 & 11.833 & 0.241 & 0.0001258 & 11.36 & 0.9989 & 0.9954 & 0.8458 \\
\hline & MP-1 & 11.906 & 0.2299 & 0.0001020 & 12.08 & 0.230 & 0.0001431 & 11.93 & 0.9856 & 0.9996 & 0.7128 \\
\hline & MP-2 & 12.684 & 0.2499 & 0.0001108 & 12.804 & 0.250 & 0.0001838 & 11.94 & 0.9906 & 0.9996 & 0.6028 \\
\hline & MP-3 & 10.474 & 0.2399 & 0.0001108 & 11.06 & 0.243 & 0.0001737 & 11.14 & 0.8882 & 0.9461 & 0.9505 \\
\hline & MB-1 & 12.268 & 0.2599 & 0.0001152 & 12.31 & 0.260 & 0.0001549 & 11.33 & 0.9966 & 0.9996 & 0.7437 \\
\hline & MB-2 & 14.11 & 0.2899 & 0.0001816 & 14.134 & 0.292 & 0.0001831 & 11.35 & 0.9983 & 0.9928 & 0.9918 \\
\hline & MB-3 & 14.326 & 0.2999 & 0.0001329 & 14.557 & 0.300 & 0.0001528 & 10.95 & 0.9841 & 0.9997 & 0.8698 \\
\hline
\end{tabular}

Note. Experimental results of the beams are borrowed from [14], and mathematical model results are borrowed from Table 5.

through finite element modelling. In order to validate the compressive and tensile stress-strain curve models, finiteelement software ATENA 3D [26] was utilized. The results of the compressive and tensile stress-strain curve models were used as preliminary input parameters.

Three material types were defined as follows:

(1) Concrete material (for plain and FRC)

(2) Steel (to model loading rod and supports)

(3) Fibre reinforcement (for FRC only)
For plain and FRC beams, material properties were essentially required. In order to define plain and FRC material, the results of the material properties obtained from the compressive and tensile stress-strain curve models were used as input parameters for the FEA. The summary of input parameters is given in Table 6.

The beams were modelled as a three dimensional solid object characterized by a material model "SBETA" by defining the user-defined material properties and material laws proposed by the researchers earlier $[10,11]$. 

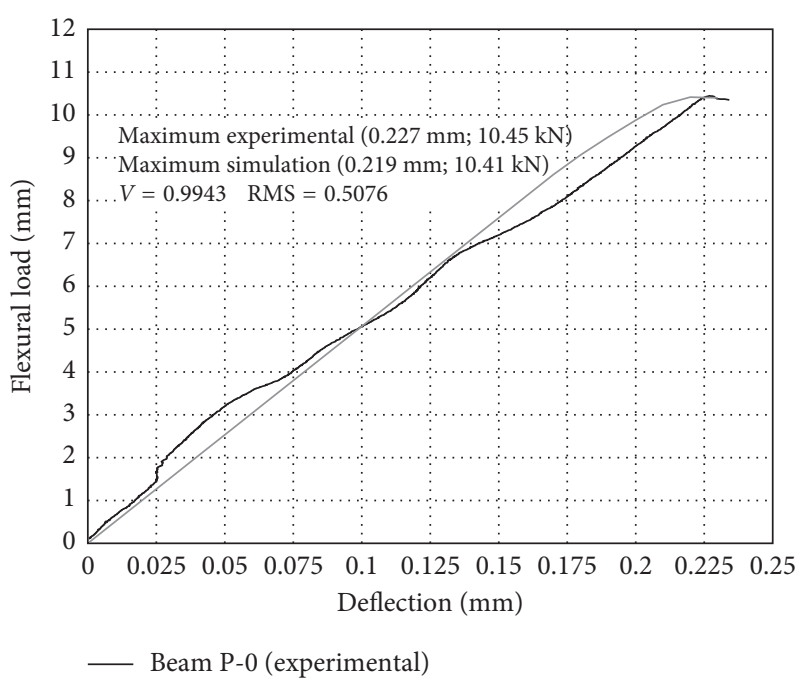

_ Beam P-0 (simulation)

(a)

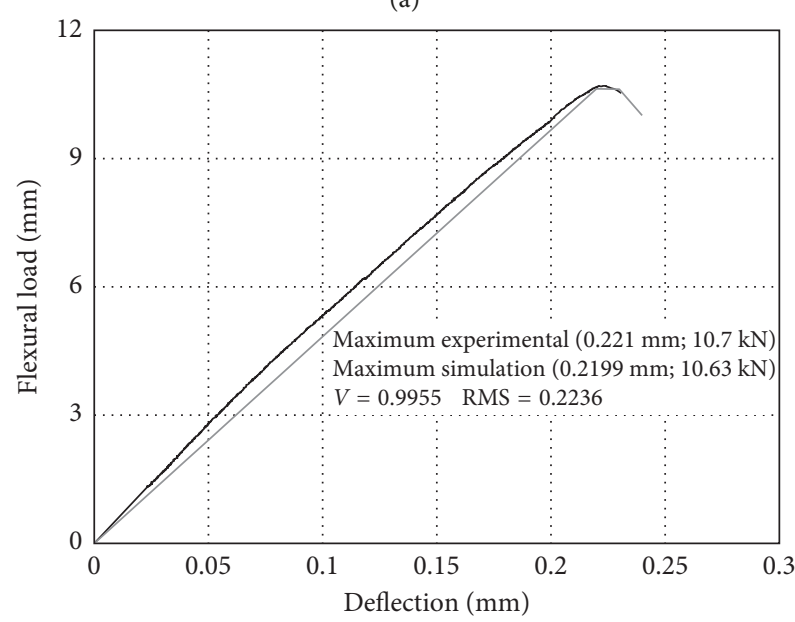

- Beam PB-1 (experimental)

_ Beam PB-1 (simulation)

(c)

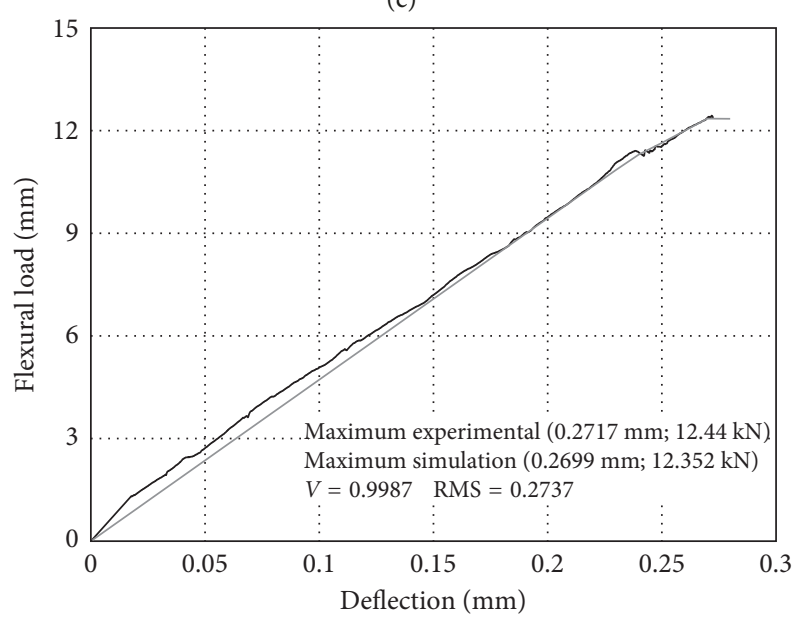

- Beam PB-2 (experimental)

— Beam PB-2 (simulation)

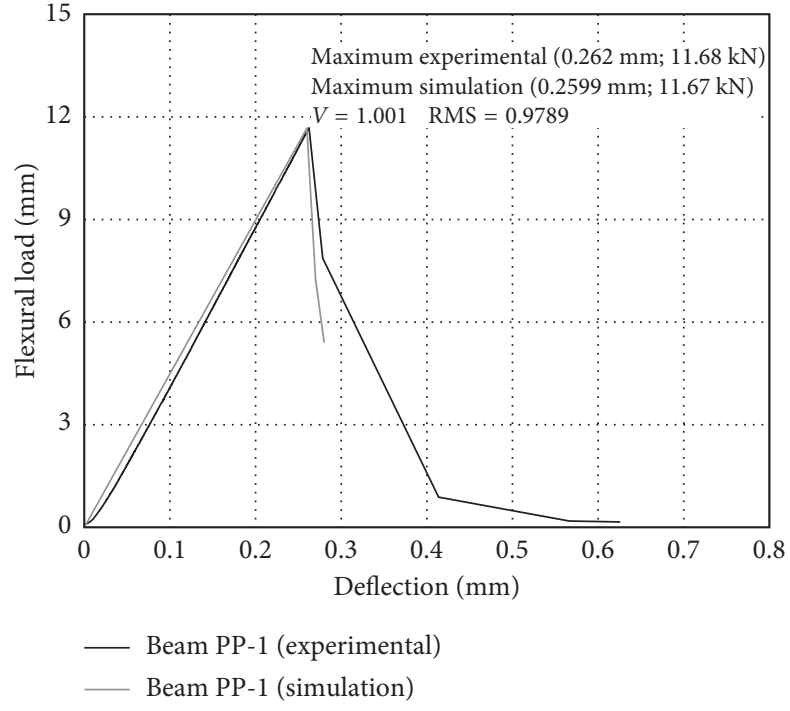

(b)

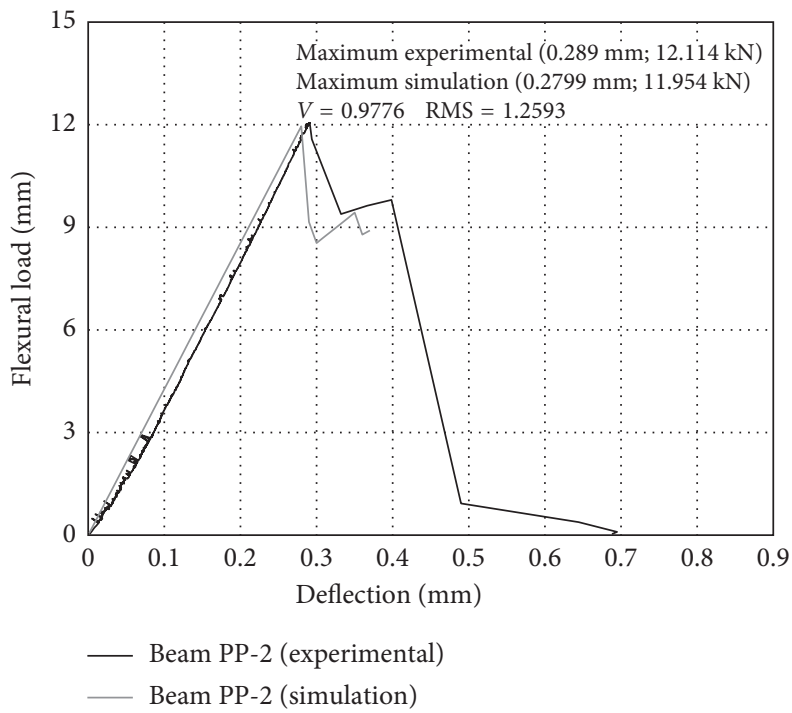

(d)

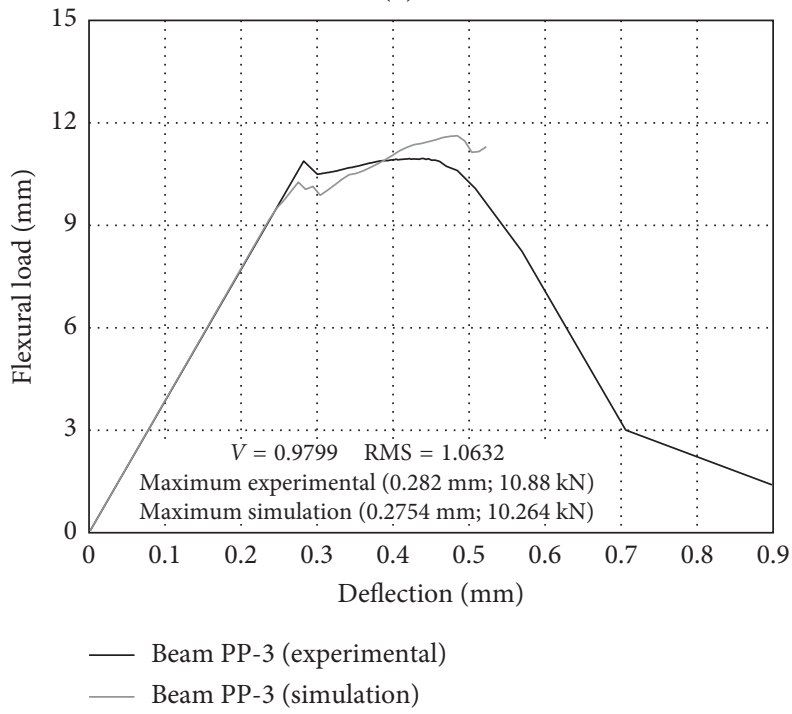

(f)

Figure 8: Continued. 


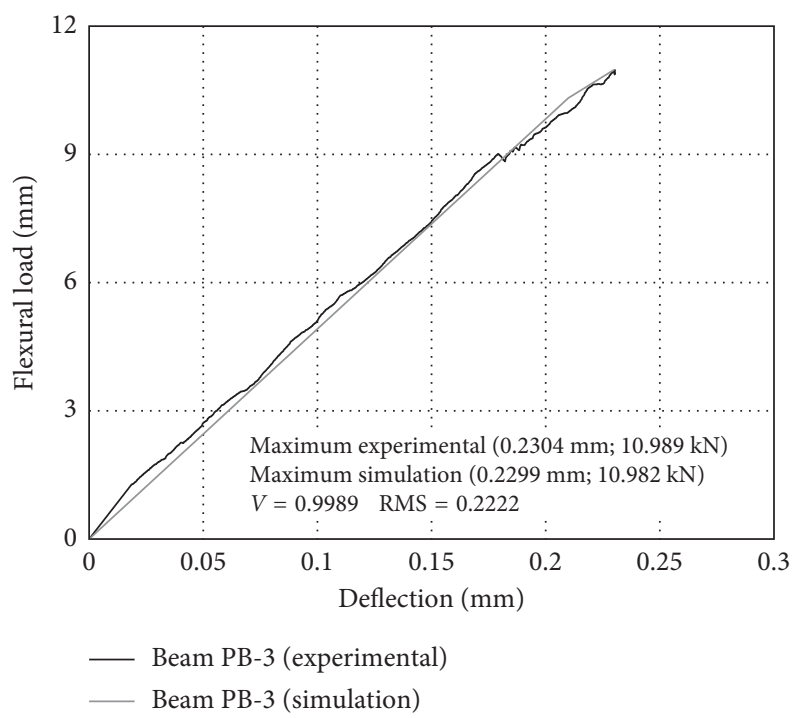

(g)

Figure 8: Experimental versus simulation load-deflection curve for series "P." (a) Beam "P-0" (without fibres). (b) Beam "PP-1" (1\% PVA fibres). (c) Beam "PB-1" (1\% basalt fibres). (d) Beam "PP-2" (2\% PVA fibres). (e) Beam "PB-2" (2\% basalt fibres). (f) Beam "PP-3" (3\% PVA fibres). (g) Beam "PB-3" (3\% basalt fibres).

It is to be noted that the aim of this investigation was to assess the accuracy of the predictive models as illustrated earlier for the compressive and tensile stress-strain behaviour of FRC containing PVA and basalt fibres in predicting the flexural response of plain and FRC beams using finite element analysis approach, which will be assessed by comparing with the experimental results of the flexural behaviour of 21 FRC beams.

All beams were modelled in full-scale mode. The dimensions of the modelled beam were $100 \times 200 \times 1500 \mathrm{~mm}$. It was assumed that FRC beams were simply supported at the bottom on semicircular steel plates, and the displacement in the direction of the beam length was set as zero (refer to Figure 6). A finite element mesh was created as a three dimensional cubical structure comprised "brick" element type with a cube size of $25 \times 25 \times 25 \mathrm{~mm}$, as shown in Figure 7. The selection of this mesh type is based on the literature review presented in [27], which recommends this mesh type for the better quality of analysis results considering the speed and memory requirements. The generated FE mesh is shown in Figure 7.

The support restrained was modelled as typical roller and hinged; that is, the movement of modelled beam was vertically and horizontally restrained. The material properties given in Table 6 were assigned to the beams, which included cylindrical compressive strength, tensile strength, modulus of elasticity, fracture energy, etc. The results of FE analysis, that is, force, displacement, and bottom strain, in the generated model were monitored to have information about the state of structure after the application of prescribed loadings. The information collected by monitoring the predefined 4 monitoring points (refer to Figure 6) is as follows:

(1) The first monitoring point was located at the middle of the beam at the top of the loading rod to monitor the maximum load attained by the beam before failure.

(2) The second monitoring point was located at the middle of the beam near its bottom surface, where largest vertical displacements can be expected. The deflections will be monitored at this location.

(3) The third and fourth monitoring points were located at $30 \mathrm{~mm}$ on the right and left side of the middle of the beam near its bottom surface to monitor the lateral displacement (similar to the tested beam given in Nasir et al. 2016). The reason for selecting $30 \mathrm{~mm}$ was the length of strain gauges used to measure the strain at the middle of the bottom face. The actual length of the strain gauges was $60 \mathrm{~mm}$. Therefore, the results of strain in the FE analysis were calculated by placing 2 monitoring points for displacements $60 \mathrm{~mm}$ apart, by subtracting their values and dividing by $0.06 \mathrm{~m}$.

For the fracture mechanism, smeared crack approach was adopted. A typical critical stress location failure pattern in the analysed beam, representative of all FRC beams, is shown in Figure 7. Three types of results were obtained from 3D nonlinear FE analysis using ATENA 3D:

(1) Maximum load (monitoring point 1) versus deflection (monitoring point 2)

(2) Failure mode (or crack pattern at failure) and the post-peak response of the concrete in the presence and absence of the fibres

(3) Lateral displacement between monitoring points 3 and 4, which were $60 \mathrm{~mm}$ apart. By dividing lateral displacement as given by ATENA 3D with $60 \mathrm{~mm}$, strain was estimated corresponding to the maximum load versus deflection 


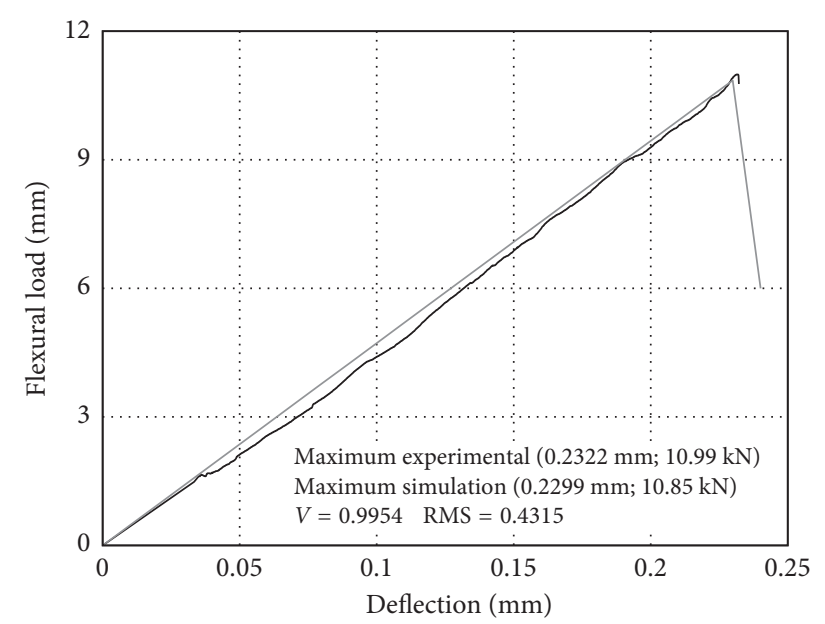

— Beam S-0 (experimental)

_- Beam S-0 (simulation)

(a)

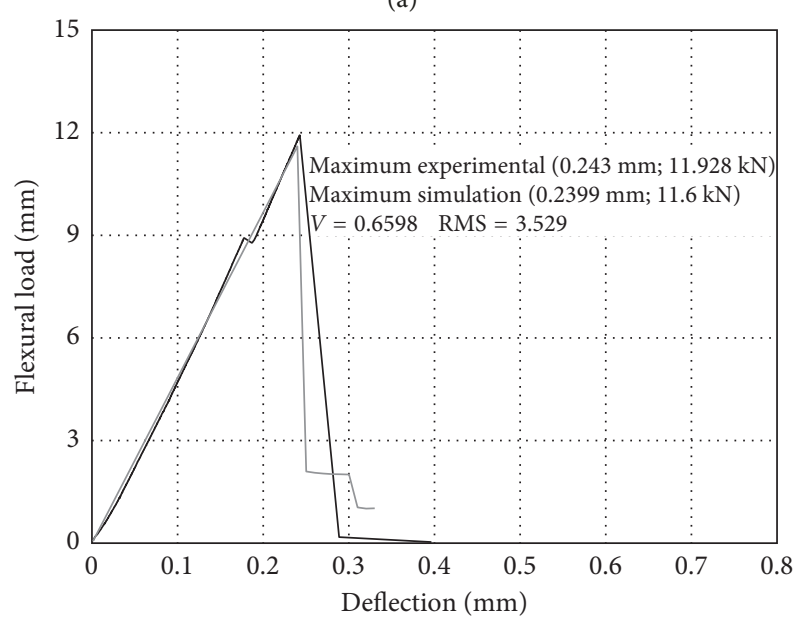

_ Beam SB-1 (experimental)

_ Beam SB-1 (simulation)

(c)

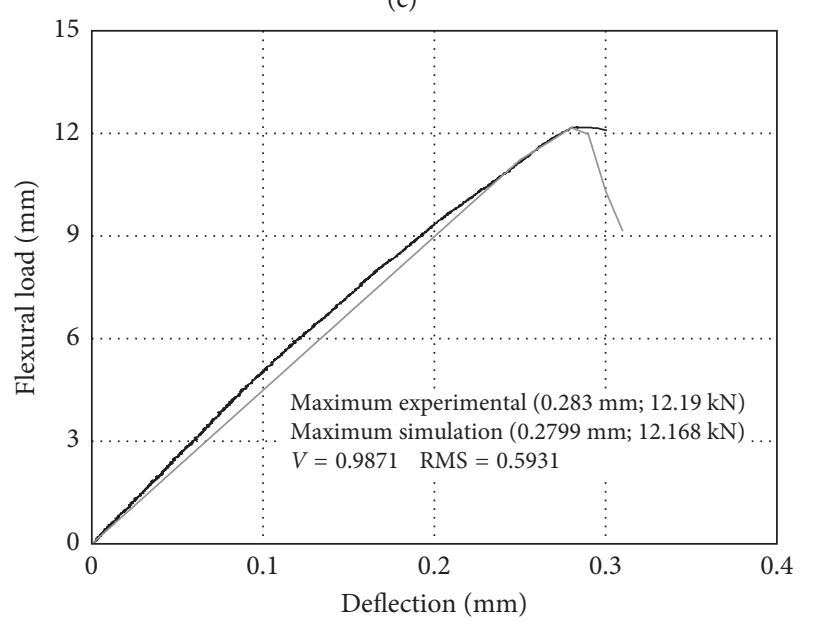

- Beam SB-2 (experimental)

_ Beam SB-2 (simulation)

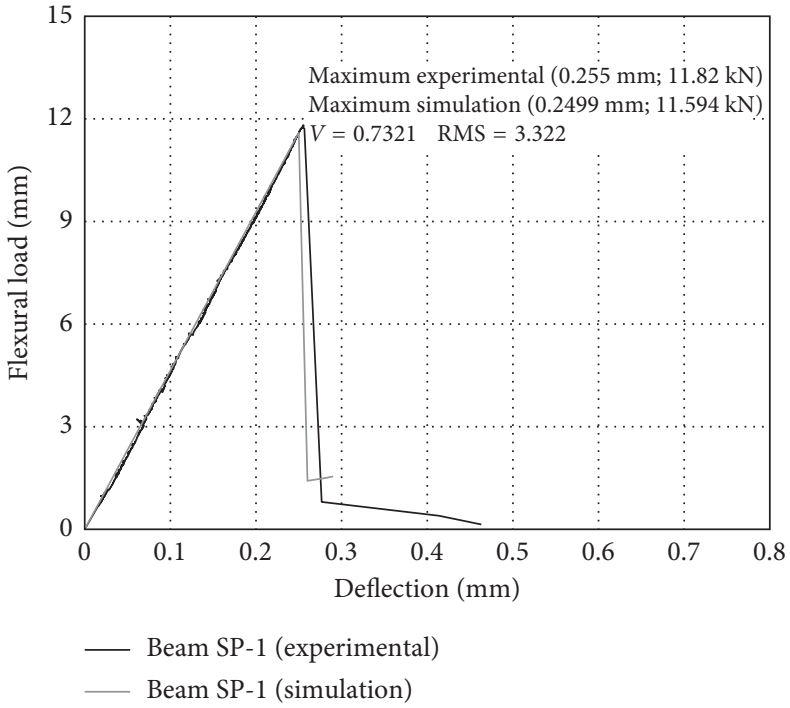

(b)

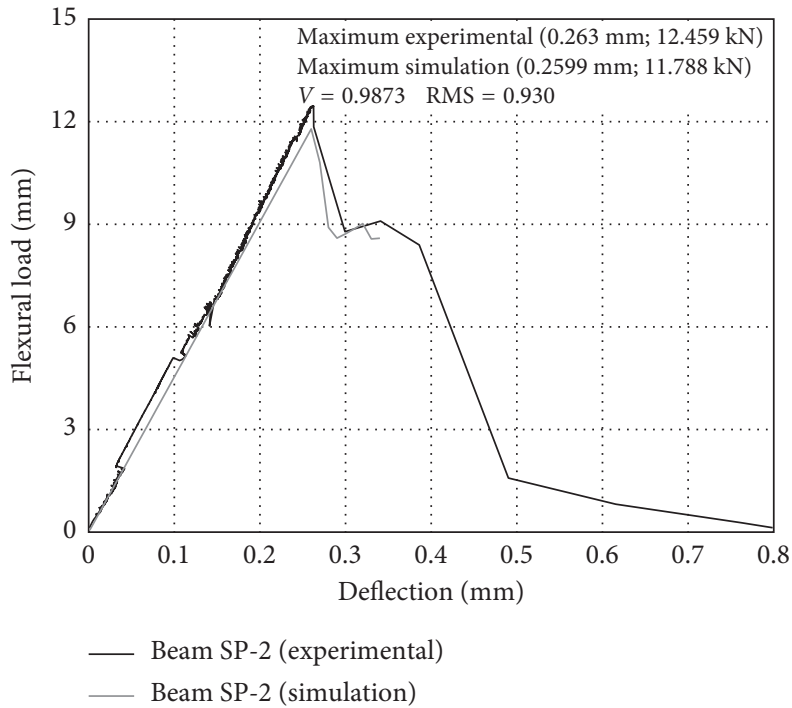

(d)

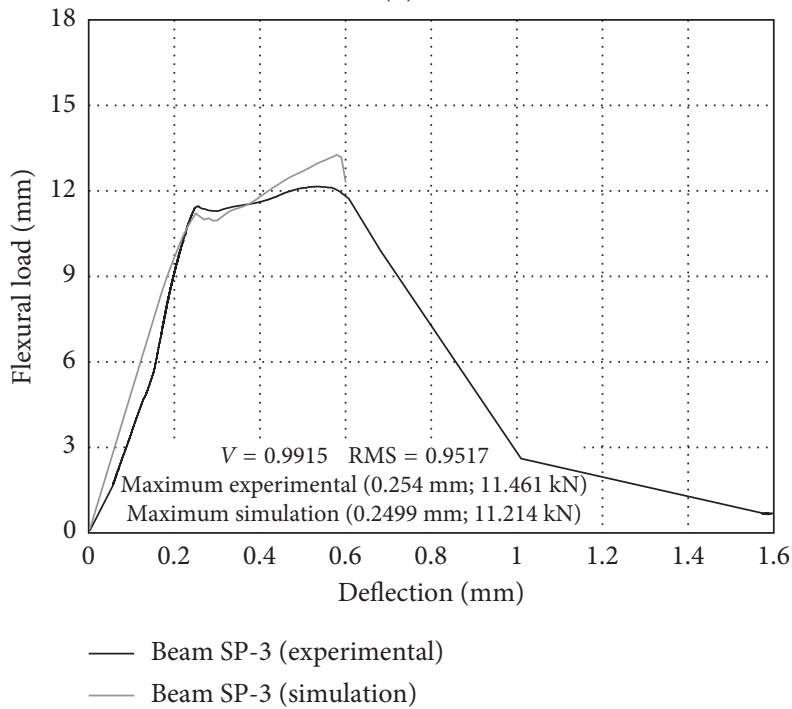

(e)

Figure 9: Continued. 


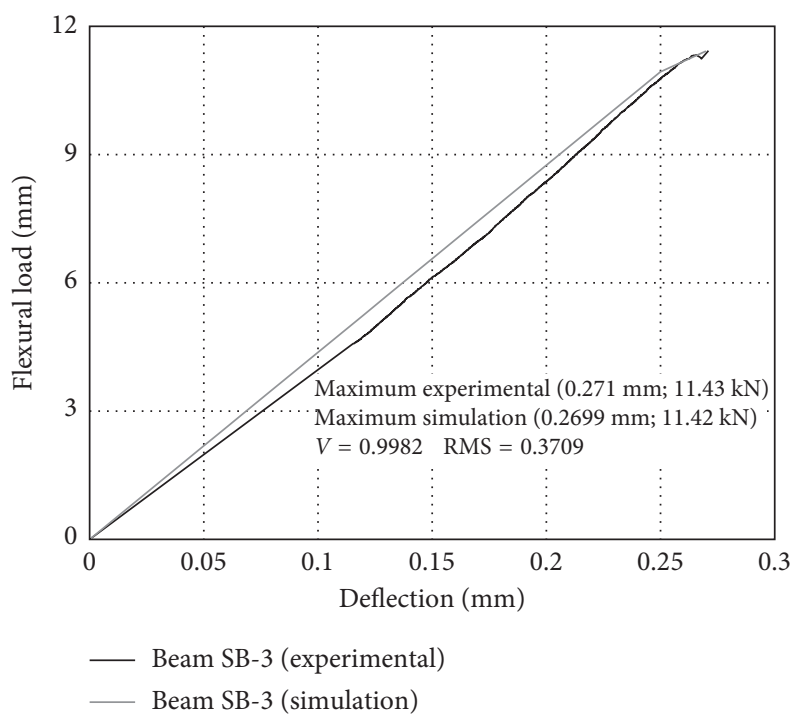

(g)

Figure 9: Experimental versus simulation load-deflection curve for series "S." (a) Beam "S-0" (without fibres). (b) Beam "SP-1" (1\% PVA fibres). (c) Beam "SB-1" (1\% basalt fibres). (d) Beam "SP-2" (2\% PVA fibres). (e) Beam "SB-2" (2\% basalt fibres). (f) Beam "SP-3" (3\% PVA fibres). (g) Beam "SB-3" (3\% basalt fibres).

The comparison of the 3D nonlinear finite element analysis results with the experimental results is presented in the forthcoming section; however, the FE analysis results and final parameters to obtain these results are summarised in Table 6.

\section{Comparison of Finite Element Analysis Results with Experimental and Mathematical Model Results}

The comparison of the finite element analysis (FEA) results with the experimental and mathematical results is presented in Table 7, which shows that the similarity of FEA results in terms of load, deflection, and tensile strain with the experimental results is more than $90 \%$. However, the results predicted with the flexural model do not match well with the finite element analysis and experimental results. This confirms that the $3 \mathrm{D}$ finite element modelling is significantly accurate compared to the mathematical model. However, the mathematical model is worthy as it is less time consuming due to no requirement of hectic modelling procedure.

The comparison of load-deflection curves and strain profile, obtained from the ATENA 3D program as a result of finite element analysis, with the experimental results is shown and discussed in the forthcoming section.

9.1. Comparison of the Load-Deflection Curves and Tensile Strain. Figure 8 shows the comparison of the simulated versus experimental load-deflection curves for the specimens of series "P" (plain concrete). Figures 9 and 10 show the comparison of the simulated versus experimental load-deflection curves for the specimens of series " $\mathrm{S}$ " (silica fume concrete) and series " $M$ " (metakaolin concrete).
The goodness of fit of the load-deflection curves shown in Figures 8-10 of the tested beams of series "P," series " $\mathrm{S}$," and series " $M$ " containing PVA and basalt fibres was determined by calculating the root mean square " $R M S$ " error and absolute fraction of variance " $V$ " manually, which showed that load-deflection responses and strain results obtained as a result of FEA are not only closed but also represent the experimental load-deflection response and strain results. The procedure for calculating " $R M S$ " and " $V$ " manually was followed from Khan et al. [28].

\section{Conclusion}

In the present paper, a flexural capacity model based on traditional equivalent rectangular stress block concept for FRC beams reinforced with PVA and basalt fibres is assessed through the experimental results of 21 beams. The model parameters for both compressive and tensile stresses were defined by allowing the conversion of the stress-strain curve models, which were suggested by the authors in earlier studies, into equivalent rectangular stress blocks, similar to Eurocode 2 and ACI 318-08.

Furthermore, the successful applicability and suitability of the analytical compressive and tensile stress-strain curve models of PVA and basalt fibre-reinforced concrete have been investigated through FEA approach in 3D nonlinear finite element analysis program ATENA 3D. The results of FEA showed approximately similar stiffness as exhibited by the tested FRC beams reinforced with 0 to $3 \%$ of PVA and basalt fibres. The results of the parameters were also close to the one obtained as a result of experimental testing.

The comparison of the results of load-deflection curves, strain profiles, and failure modes of FRC beams obtained as 


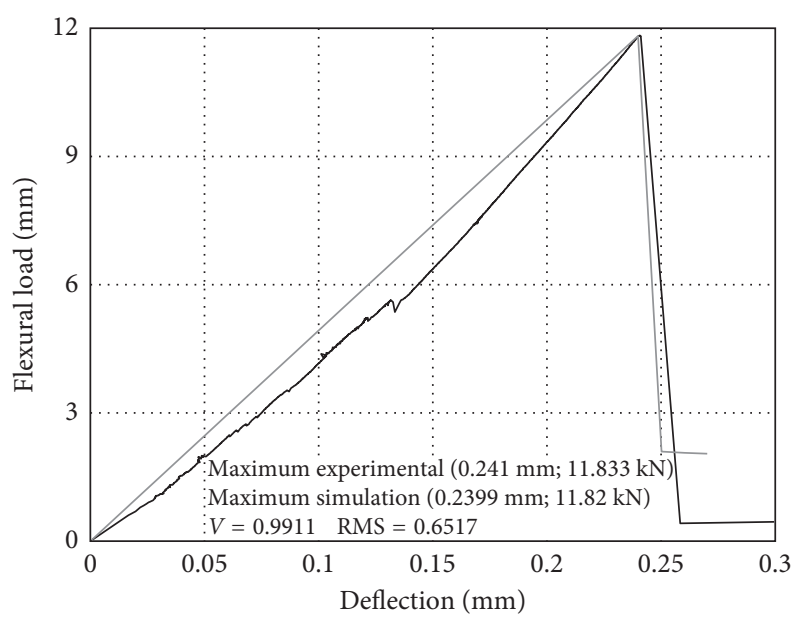

— Beam M-0 (experimental)

— Beam M-0 (simulation)

(a)

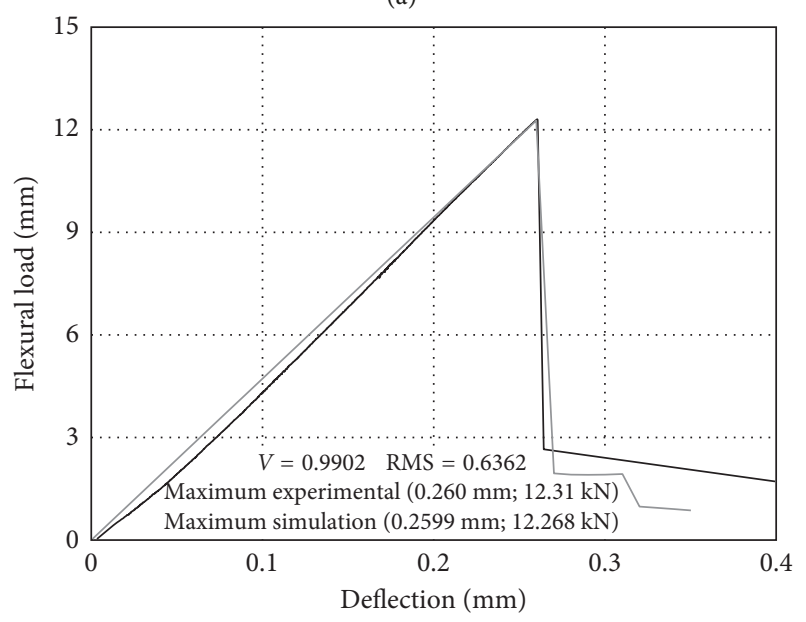

- Beam MB-1 (experimental)

__ Beam MB-1 (simulation)

(c)

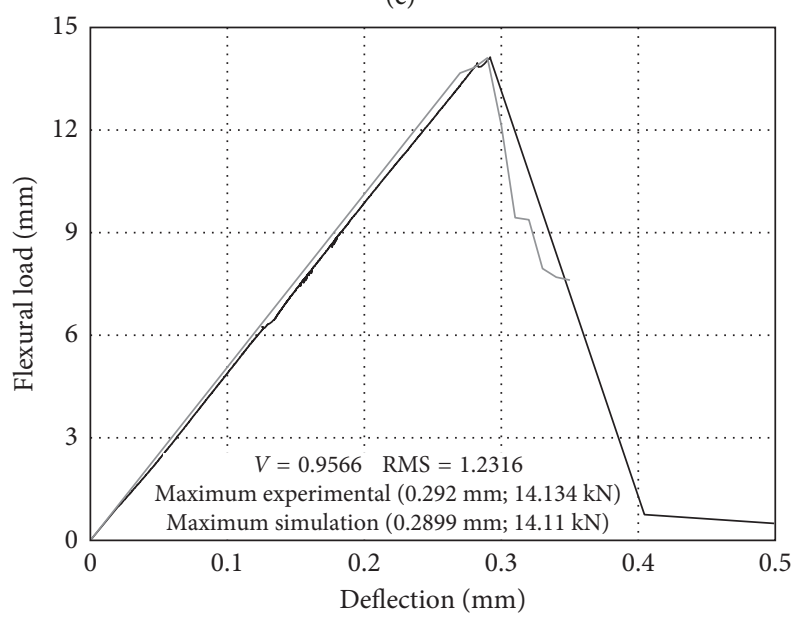

- Beam MB-2 (experimental)

Beam MB-2 (simulation)

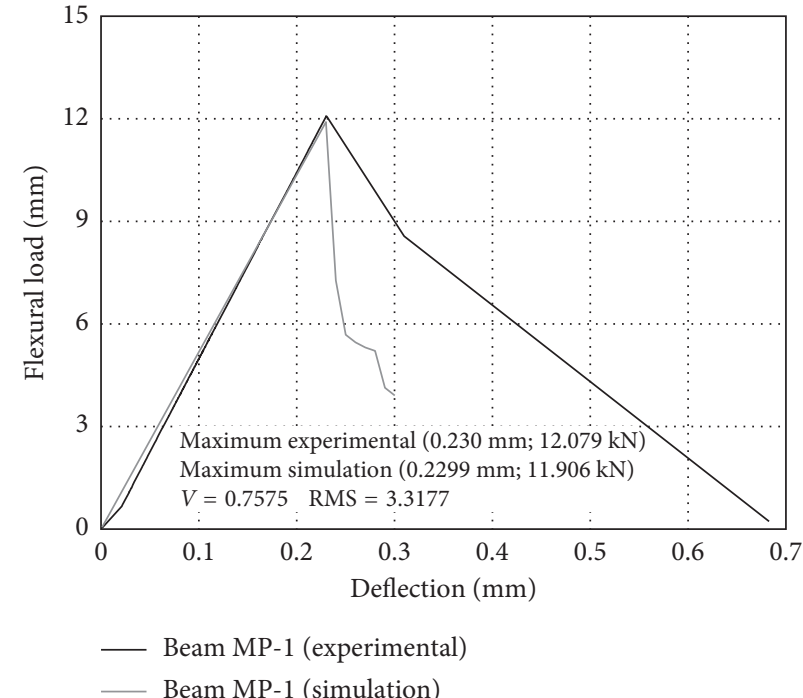

(b)

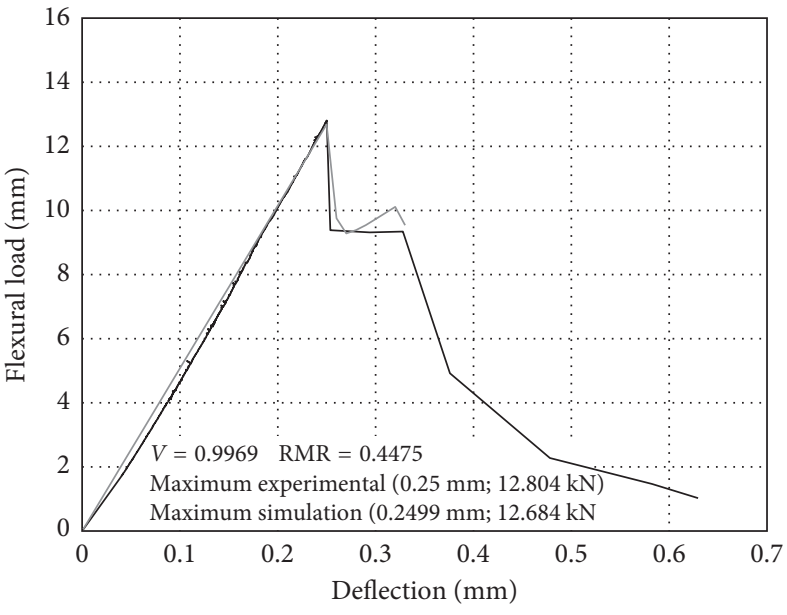

- Beam MP-2 (experimental)

- Beam MP-2 (simulation)

(d)

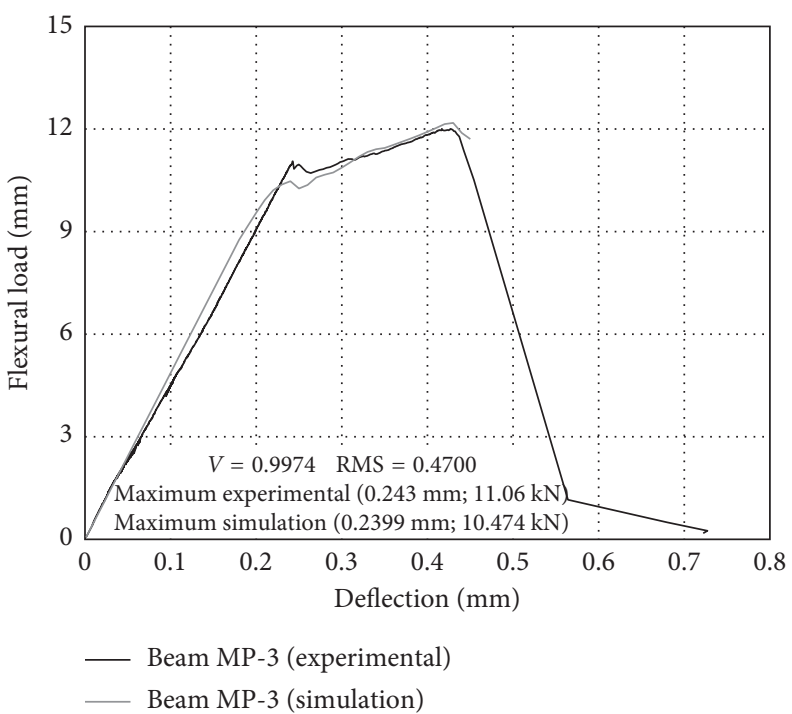

(e)

(f)

Figure 10: Continued. 


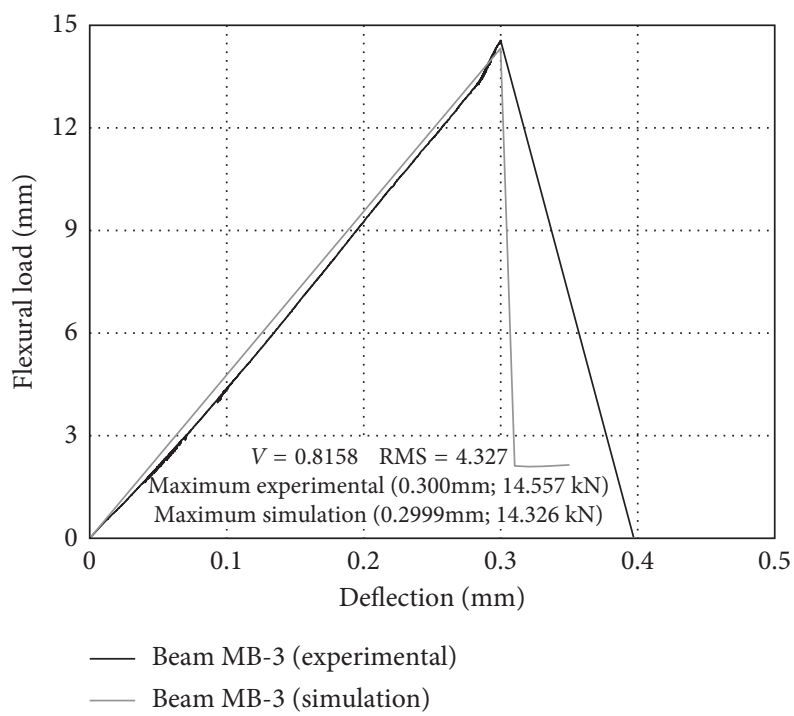

(g)

FiguRE 10: Experimental versus simulation load-deflection curve for series "M." (a) Beam "S-0" (without fibres). (b) Beam "SP-1" (1\% PVA fibres). (c) Beam "SB-1" (1\% basalt fibres). (d) Beam "SP-2" (2\% PVA fibres). (e) Beam "SB-2" (2\% basalt fibres). (f) Beam "SP-3" (3\% PVA fibres). (g) Beam "SB-3" (3\% basalt fibres).

a result of finite element results using "ATENA 3D program” showed close agreement with the experimental results.

\section{Notations}

$E_{o}$ or $E_{\mathrm{it}}: \quad$ Initial modulus of elasticity calculated from compressive stress-strain curve

$E_{c}$ : $\quad$ Secant modulus of elasticity calculated from compressive stress-strain curve

$E_{c f}: \quad$ Modulus of elasticity of FRC

$E_{\mathrm{ct}}$ : Modulus of elasticity of the composite

$E_{m}$ : $\quad$ Modulus of elasticity of the concrete matrix without fibre

$E_{c f}: \quad$ Modulus of elasticity of FRC

$E_{0 f}: \quad$ Secant modulus of elasticity

$E_{f}$ : $\quad$ Modulus of elasticity of fibre

$\varepsilon: \quad$ Strain

$\varepsilon_{0}$ : $\quad$ Strains corresponding to $f^{\prime}$

$\varepsilon_{0 f}$ : Compressive strain corresponding to the maximum stress $\left(f_{c f}^{\prime}\right)$ of FRC

$\varepsilon_{c}: \quad$ Strain corresponding to the effective peak compressive strength of concrete, $f^{\prime e f}$

$\varepsilon_{c, \text { lim }}$ : Compressive strain corresponding to the limiting stress $\left(f_{c, \text { lim }}\right)$ in the post-peak branch of the stress-strain curves of FRC

$\varepsilon_{\mathrm{cr}}$ or $\varepsilon_{t}^{\prime}$ : Concrete cracking strain

$\varepsilon_{\mathrm{cu}}: \quad$ Ultimate compressive strain

$\varepsilon_{\mathrm{tu}}$ : $\quad$ Ultimate tensile strain corresponding to $\sigma_{\mathrm{pc}}$

$\varepsilon_{\mathrm{cu}}$ : $\quad$ Ultimate compressive strain assumed as 0.0035

$F_{t(\mathrm{pc})}$ : $\quad$ Flexural load at ultimate

$F_{t}: \quad$ Flexural load at cracking

$f_{c}^{\prime}$ : $\quad$ Maximum compressive stress of plain concrete

$f_{c f}^{\prime}$ : Maximum compressive stress of FRC

$f_{t}^{\prime}$ : $\quad$ Maximum tensile stress of plain concrete $f_{\text {tf }}^{\prime}$ or $\sigma_{\text {cc }}$ : Maximum tensile strength/stress of FRC

$f_{\mathrm{pc}}$ or $\sigma_{\mathrm{pc}}$ : Tensile stress after cracking

$M_{\mathrm{cr}}$ : $\quad$ Flexural capacity or moment capacity of FRC at stress

$n$ : $\quad$ Material parameter in compressive stress-strain curve modelling

$P_{\mathrm{cr}}: \quad$ Load corresponding to cracking

RMS: $\quad$ Root mean square errors

$V: \quad$ Absolute fraction of variance

$V_{f}: \quad$ Volume fraction of the fibres

$\omega$ : $\quad$ Material parameter used for predicting tensile stress-strain curves.

\section{Conflicts of Interest}

The authors declare that there are no conflicts of interest regarding the publication of this paper.

\section{References}

[1] A. M. Brandt, "Fibre reinforced cement-based (FRC) composites after over 40 years of development in building and civil engineering," Composite Structures, vol. 86, no. 1-3, pp. 3-9, 2008.

[2] J.-L. Granju and S. U. Balouch, "Corrosion of steel fibre reinforced concrete from the cracks," Cement and Concrete Research, vol. 35, no. 3, pp. 572-577, 2005.

[3] C. Jiang, K. Fan, F. Wu, and D. Chen, "Experimental study on the mechanical properties and microstructure of chopped basalt fibre reinforced concrete," Materials \& Design, vol. 58, pp. 187-193, 2014.

[4] K. Holschemacher and S Höer, "Influence of PVA fibers on load carrying capacity of concrete with coarse aggregates," in Proceedings of the Seventh International Rilem Symposium on Fibre Reinforced Concrete: Design and Applications, pp. 219229, Chennai, India, 2008. 
[5] M. H. T. Haskett, M. Sadakkathulla, M. A. Sahib et al., "Deflection of GFRP and PVA fibre reinforced concrete beams," in Proceedings of the International Conference on FRP Composites in Civil EngineeringCICE 20122012, Rome, Italy, 2012.

[6] V. C. Li, S. Wang, and C. Wu, "Tensile strain-hardening behavior of polyvinyl alcohol engineered cementitious composite (PVA-ECC)," ACI Materials Journal-American Concrete Institute, vol. 98, no. 6, pp. 483-492, 2001.

[7] M. F. Nuruddin, S. U. Khan, N. Shafiq, and T. Ayub, "Strength development of high-strength ductile concrete incorporating metakaolin and PVA fibers," The Scientific World Journal, vol. 2014, Article ID 387259, 11 pages, 2014.

[8] Z. B. Kan and Y. R. Li, "Analysis on mechanical properties and durability of the chopped basalt fiber reinforced concrete," Advanced Materials Research, vol. 598, pp. 627-630, 2012.

[9] T. Ayub, N. Shafiq, and M. F. Nuruddin, "Effect of chopped basalt fibers on the mechanical properties and microstructure of high performance fiber reinforced concrete," Advances in Materials Science and Engineering, vol. 2014, Article ID 587686, 14 pages, 2014.

[10] T. Ayub, N. Shafiq, and S. U. Khan, "Compressive stress-strain behavior of HSFRC reinforced with basalt fibers," Journal of Materials in Civil Engineering, vol. 28, no. 4, p. 06015014, 2015.

[11] S. U. Khan and T. Ayub, "Modelling of the pre and postcracking response of the PVA fibre reinforced concrete subjected to direct tension," Construction and Building $\mathrm{Ma}$ terials, vol. 120, pp. 540-557, 2016.

[12] P. A. Jones, S. A. Austin, and P. J. Robins, "Predicting the flexural load deflection response of steel fibre reinforced concrete from strain, crack-width, fibre pull-out and distribution data," Materials and Structures, vol. 41, no. 3, pp. 449463, 2008.

[13] J. A. O. Barros and J. A. Figueiras, "Flexural behavior of SFRC: testing and modeling," Journal of Materials in Civil Engineering, vol. 11, no. 4, pp. 331-339, 1999.

[14] N. Shafiq, T. Ayub, and S. U. Khan, "Investigating the performance of PVA and basalt fibre reinforced beams subjected to flexural action," Composite structures, vol. 153, pp. 30-41, 2016.

[15] International A. C192/C192M, Standard Practice for Making and Curing Concrete Test Specimens in the Laboratory, ASTM International, West Conshohocken, PA, USA, 2016.

[16] T. Ayub, N. Shafiq, and M. F. Nuruddin, "Stress-strain response of high strength concrete and application of the existing models," Research Journal of Applied Sciences, Engineering and Technology, vol. 8, no. 10, pp. 1174-1190, 2014.

[17] L. S. Hsu and C.-T. T. Hsu, "Complete stress-strain behaviour of high-strength concrete under compression," Magazine of Concrete Research, vol. 46, no. 169, pp. 301-312, 1994.

[18] M. A. Mansur, M. S. Chin, and T. H. Wee, "Stress-strain relationship of high-strength fiber concrete in compression," Journal of Materials in Civil Engineering, vol. 11, no. 1, pp. 21-29, 1999.

[19] ACI Committee 363, State-of-the-Art Report on High-Strength Concrete (ACI 363R-92), American Concrete Institute, Farmington Hills, MI, USA, 1992.

[20] ACI Committee 318, Building Code Requirements for Structural Concrete (ACI 318-08) and Commentary, American Concrete Institute, Farmington Hills, MI, USA, 2008.

[21] CSA Technical Committee, Design of Concrete Structures for Buildings (CAN3-A23. 3-94), Canadian Standards Association, Rexdale, Ontario, Canada, 1994.
[22] BS EN 1992-1-1, Eurocode 2-Design of Concrete Structures: Part 11: General Rules and Rules for Buildings, European Committe for Standardisation, Brussel, Belgium, 2004.

[23] T. Ayub, Analytical Modelling and Finite Element Analysis of FRC Beams Containing PVA and Basalt Fibres, Universiti Teknologi Petronas, Bota, Perak, Malaysia, 2015.

[24] T. Ayub and S. U. Khan, "Finite element modelling of FRC beams containing PVA and basalt fibres: a comparative study," AIP Conference Proceedings, vol. 1872, no. 1, p. 020002, 2017.

[25] C. Soranakom and B. Mobasher, "Closed-form solutions for flexural response of fiber-reinforced concrete beams," Journal of Engineering Mechanics, vol. 133, no. 8, pp. 933-941, 2007.

[26] V. Červenka and L. Jendele, ATENA Program Documentation Part 8, Cervenka Consulting s.r.o., Prague, Czech Republic, 2000.

[27] V. Červenka, L. Jendele, and J. Červenka, ATENA Program Documentation, Part 1: Theory, Cervenka Consulting s.r.o., Prague, Czech Republic, 2007.

[28] S. U. Khan, T. Ayub, and S. F. A. Rafeeqi, "Prediction of compressive strength of plain concrete confined with ferrocement using artificial neural network (ANN) and comparison with existing mathematical models," American Journal of Civil Engineering and Architecture, vol. 1, no. 1, pp. 7-14, 2013. 


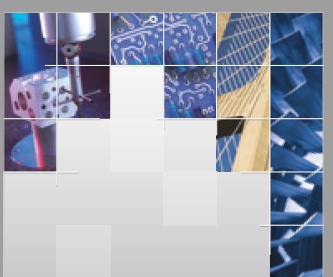

\section{Enfincering}
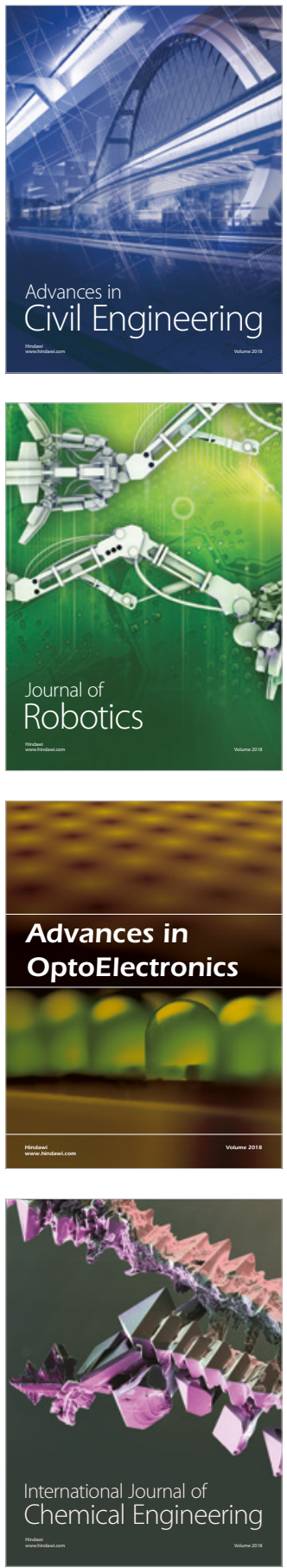

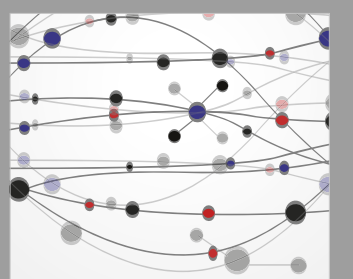

\section{Rotating \\ Machinery}

The Scientific World Journal

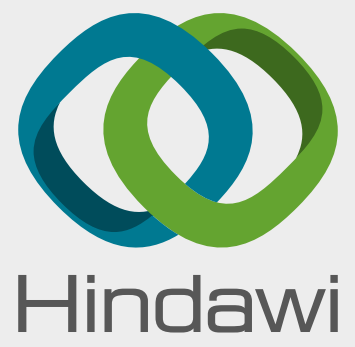

Submit your manuscripts at

www.hindawi.com
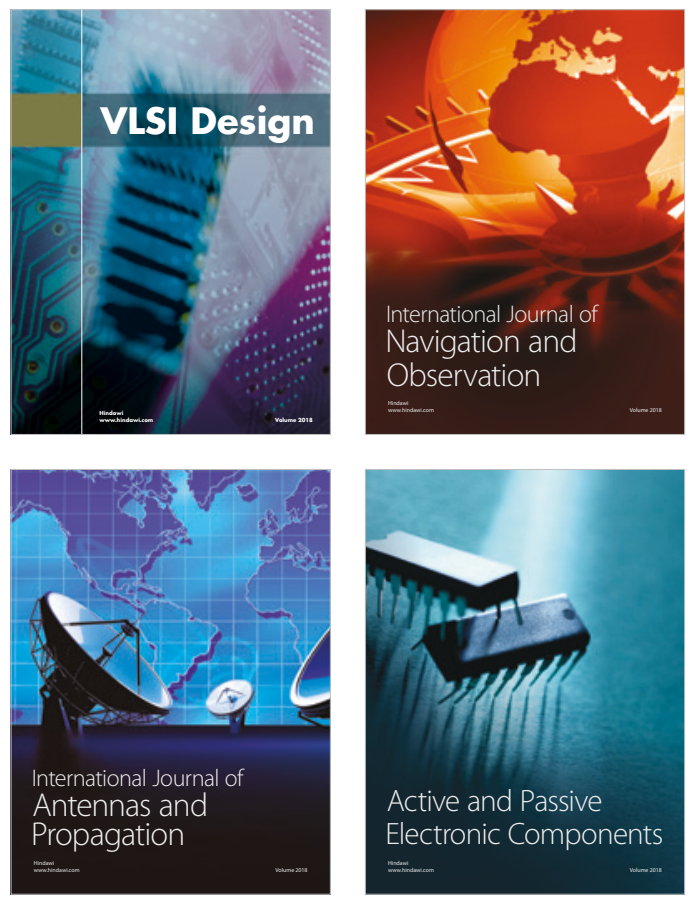
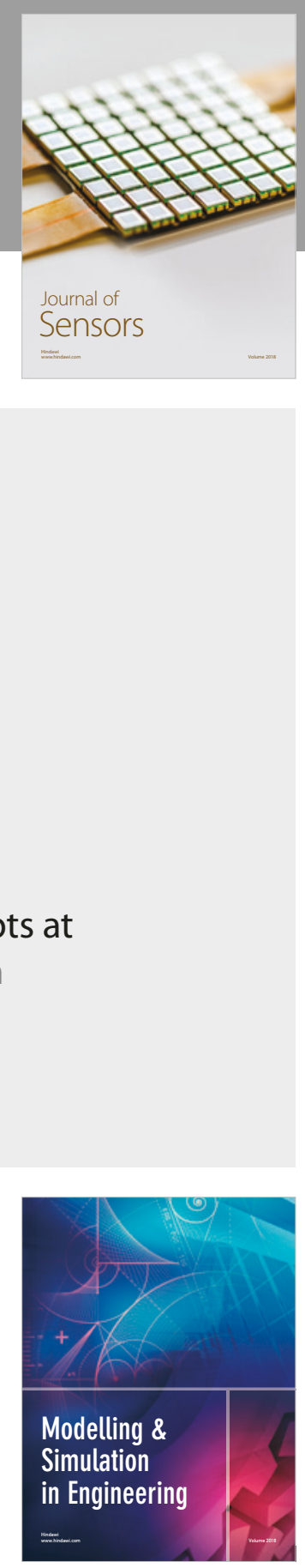

\section{Advances \\ Multimedia}
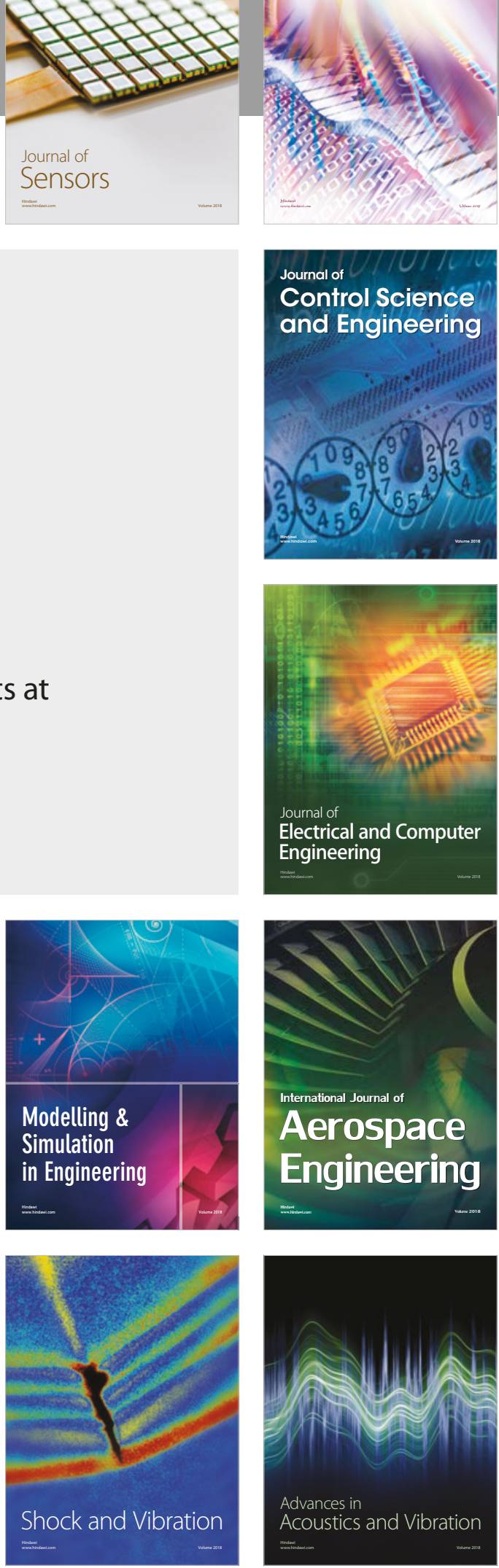